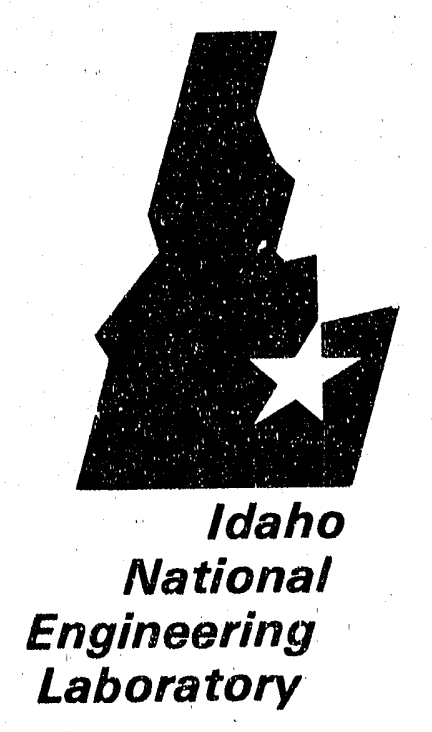

EGG-WTD-9901

December 1991

Alter 1092

Physical and Chemical Properties of the Products of In Situ Vitrification Engineering Tests 5, 6, and 7

\author{
Managed \\ by the U.S. \\ Department \\ of Energy
}

C. A. Loehr

J. R. Weldner

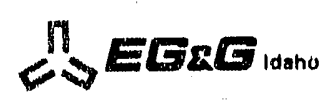

Work pertormed under DOE Contract
No. DE-ACO7-761D01570 
This document contains new concepts or the author(s) interpretation of new calculations and/or measurements; accordingly, EG\&G Idaho, Inc. is required by the United States Government to include the following disclaimer:

\section{DISCLAIMER}

This report was prepared as an account of work sponsored by an agency of the United States Government. Neither the United St.lles Government nor any agency thereof, nor any of their employees, makes any w'arranty, express or implied, or assumes any legal llability or responsibility for the accuracy, completeness, or usefulness of any information, apparatus, product $v$ process disclosed, or represents that its use would not infringe privately owned nights. References herein to any specific commercial product, process, or service by trade name, trademark, manufacturer, or othenwise, does not necessarily constitute or imply its endorsement, recommendation, or favoring by the United States Government or any agency thereof. The views and opinions of authors expressed herein do not necessarily state or reflect those of the United States Government or any agency thereot. 


\title{
Physical and Shemical Properties of the Products of In Situ Vitrification Engineering Tests 5, 6 and 7
}

\author{
C. A. Loehr \\ J. R. Weidner \\ Published December 1991
Idaho National Engineering Laboratory EG\&G Idaho, Inc. Idaho Falls, Idaho 83415


Physical and Chemical Properties of the Products of In Situ Vitrification Engineering Tests 5, 6, and 7

EGG-WTD-9901

Prepared by:
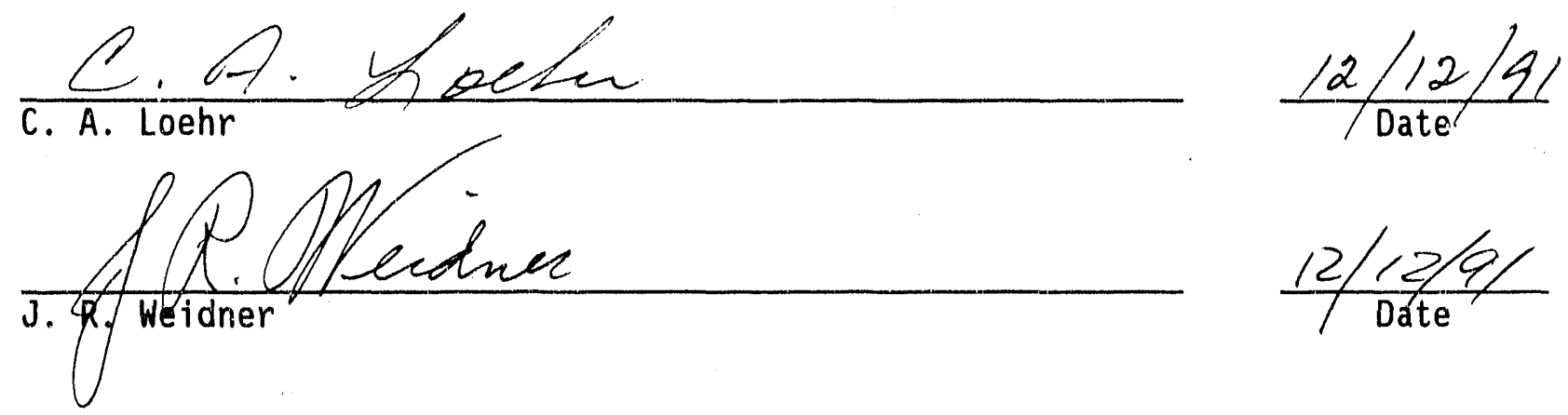

Reviewed and Approved by:

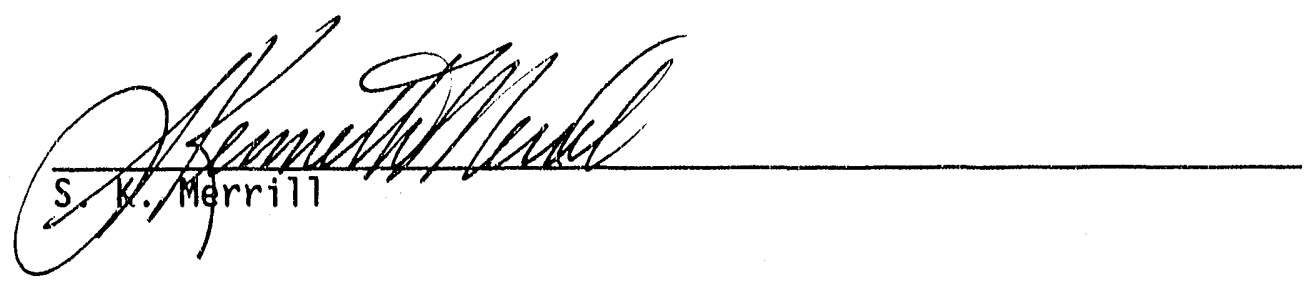

$$
\frac{12 / 12 / 91}{\text { Date }}
$$




\section{ABSTRACT}

The physical and chemical properties of the in situ vitrification (ISV) waste forms produced by engineering-scale tests (ES) ES-5, ES-6, and ES-7 are described in this report. The ISV waste forms, or products, resulted from vitrification of sealed containers of sludge. The sludge was a composite of hazardous organic materials, petroleum products, nitrates, calcium silicate, and mercuric and other inorganic oxides. The sludge simulated the waste found at the Idaho National Engineering Laboratory (INEL) Subsurface Disposal Area (SDA). Megascopic and microscopic characteristics of the product material are described in this report. The microscopic properties were determined using planepolarized light microscopy and the electron microprobe.

The products from ES-5, ES-6, and ES-7 are megascopically quite similar, despite test configuration differences that could produce differences in cooling time and product composition. The products are glass, contain metallic and crystalline phases, and exhibit a gray-vesiculated rind about $10 \mathrm{~mm}$ thick. The metallic phases are present in the glass as round inclusions, microscopic to about $3 \mathrm{~mm}$ in diameter. The inclusions are either rich in silicon or rich in phosphorous, the latter as a rim on a pure iron center. The glass composition and distribution of metallic inclusions provide direct evidence that the graphite electrodes used in the process reduce iron dissolved in the melt to the metallic state during ISV processing. Remnant soil quartz grains are associated both with crystalline material and with vesicles, suggesting that quartz affects the occurrence of crystalline and gaseous phases.

The waste and waste containers were mpletely processed in the samples observed, except in and near the rind of some samples where portions of containers were intact. Product edges exhibit heterogeneous compositions, but the glassy phase is generally homogeneous at the macroscale.

The average chemical compositions of ES- $\delta$ and ES-7 glasses are approximately similar to the average glass compositions measured in previous INEL tests. Leach testing on products of the previous tests indicate that their chemical durability is comparable to obsidian and granite and substantially more durable than typical high-level nuclear waste bornsilicate glasses. The ES- 6 
and ES-7 glasses will have chemical durability characteristics similar to these products because chemical durability of glass is a function of chemical composition. In addition, because the ES- 6 and ES-7 glasses are andesitic in composition, they will probably be stable in the natural environment for time periods similar to their natural counterpart. 


\section{CONTENTS}

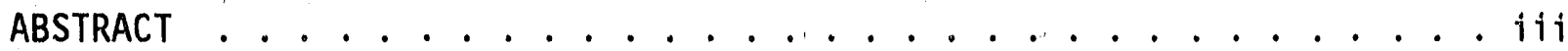

ACRONYMS ......................... . . ix

INTRODUCTION ............................. . . . 1

Product Evaluation Objectives .................. 2

Previous Work ....................... . 3

Test Descriptions . . . . . . . . . . . . . . . . . . 4

Test Objectives and Designs . . . . . . . . . . . . . . 4

Test Operations and Results ................ 5

PHYSICAL AND CHEMICAL PROPERTY CHARACTERIZATION . . . . . . . . . . . 9

Sampling and Analysis Strategy ................. . . 9

Megascopic Description ................. . 9

Microscopic Properties ................... 13

Analysis Techniques ................... 16

Microscopic Properties .................. . 16

Analysis Results and Discussion . . . . . . . . . . . . 18

Hand Specimen Descriptions . . . . . . . . . . . . . 18

Microscopic Properties .................. . . 26

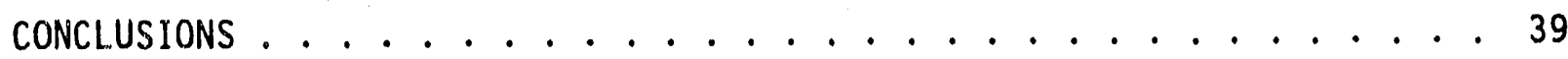

REFERENCES ......................... . 41

Appendix A--Qualitative Electron Microprobe Analysis . . . . . . . A-1

\section{FIGURES}

1. Photograph of sample IC201A90E5 showing glass adjacent to soil contact. (Photograph by L. A. Shelley)

2. Photograph of sample IC201A90E5 showing contact soil material.

(Photograph by L. A. Shelley) ................. . 12

3. Photograph of sample IC501A90E6 showing electrode imprint in glass. Soil contact is under the specimen as shown.

(Photograph by L. A. Shelley) ................. 14

4. Photograph of sample IC503A90ES showing outline of large bubble in glass. (Photograph by L. A. Shelley) 
5. Photograph of rind in subsample IC502B90E6 at 100 times magnification shown in plane polarized light with (a) no crossed nicol prisms and (b) crossed nicol prisms.

(Photographs by C. R. Knowles.) . . . . . . . . . . . . . . 28

6. Petrographic polished thin section of subsample IC405D90E7.

Glass stide measures $4.6 \times 2.7 \mathrm{~cm}$.

(Photograph by C. R. Knowles.) . . . . . . . . . . . . 30

7. Photograph of glass with vesicles and quartz grains in subsample

IC502B90E6 at 100 times magnification shown in plane-polarized

light with (a) no crossed nicol prisms and (b) crossed nicol

prisms. (Photographs by C. R. Knowles.) ............. 32

8. Electron microprobe backscatter electron image of quartz in subsample IC501B90E6 at 200 times magnification. (Photograph by C. R. Knowles.)

9. Photograph of glass at electrode contact in subsample IC502B90E6 at 100 times magnification shown in (a) planepolarized transmitted light with no crossed nicol prisms and (b) reflected light. Glass is shown in the bottom portion of the photographs. (Photographs by C. R. Knowles.) . . . 34

10. X-ray dot map images of metallic iron inclusion with phosphorous rim in subsample IC408B90E7. Shown are (a) $\mathrm{Fe}$ $x$-ray scan and (b) $P$ x-ray scan at 1000 times magnification. (Photographs by C. R. Knowles.)

\section{TABLES}

1. Compositions of sludge series used in ES-5 in wt\% . . . . . . . . 6

2. INEL soil compositions measured for ISV tests (NM = Not Measured) . . 7

3. Composition of siudge used in ES-6 and ES-7

(from References 10 and 11 ) ................ 8

4. Analyses performed on subsamples . . . . . . . . . . . . . 17

5. Quantitative electron inicroprobe analyses for subsamples of sample IC007A90IE performed by Idaho Geological Survey.

Analyses are reported in wt\% ................ . 19

6. Index of refraction results . . . . . . . . . . . . . . . 27

7. Microchemical analysis of subsamples from ES-6 and ES-7 in wt\% . . . 29

8. Microchemical analysis of metal inclusions in subsamples from

ES-6 and ES-7 in wt\% ................. . . 31 
9. Average major element composition in weight percent of glasses from products of INEL tests. Standard errors of averages are shown in parentheses 


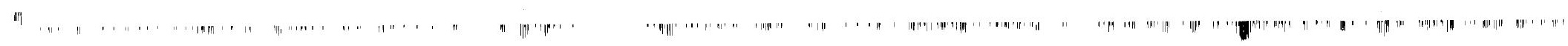




\section{ACRONYMS}

BSE

backscattered electron

CERCLA

Comprehensive Environmental Response, Compensation, and Liability Act

EDS

energy dispersive $x$-ray spectrometry

ES

engineering-scale (test)

INEL

Idaho National Engineering Laboratory

ISV

in situ vitrification

NIST

National Institute of Standards and Technology

PCT

Product Consistency Test

PNL

Pacific Northwest Laboratory

SDA

Subsurface Disposal Area

TCLP

toxicity characterization leaching procedure 


\section{Physical and Chemical Properties of the Products of In Situ Vitrification Engineering Tests 5, 6, and 7}

\section{INTRODUCTION}

In situ vitrification (ISV) is an in situ thermal treatment process that is being investigated by the Idaho National Engineering Laboratory (INEL) for application to buried waste sites. ISV is a thermal treatment process that converts contaminated soil into a chemically inert and stable glass and crystalline product. The INEL is evaluating whether the treatment process is a viable one for remediating a buried mixed transuranic waste site at the INEL subsurface Disposal Area (SDA). The SDA is a Comprehensive Environmental Response, Compensation, and Liability Act (CERCLA) site.

As part of the INEL investigation, a series of tests have been performed that address issues associated with vitrification of buried waste. Two pilot ISV tests and four tests at Taboratory scale, formerly called engineering scale, were performed in 1990 to support the INEL investigation. The physical and chemical properties of three of the tests, Engineering-Scale Test $5(E S-5)$, Engineering-Scale Test 6 (ES-6), and Engineering-Scale Test 7 (ES-7), are the subject of this report. The ES-5, ES-6, and ES-7 test objectives focused on determining the effect of ISV on sealed containers of sludge. The sludge used simulated waste found at the INEL SDA. The sludge was a composite of materials including hazardous organic materials, petroleum products, nitrates, calcium silicate, and mercuric and other inorganic oxides.

Reports describing test operations and process results are being prepared by the test performers at this writing. Pacific Northwest Laboratory (PNL) performed ES-5 and Geosafe Corporation, Kirkland, Washington, performed ES-6 and F.S-7. Chemical durability studies on all three test products are being performed by PNL and will be published in a separate report.

In the subsequent section, the objectives of the ISV product evaluation for the INEL investigation, and for the ES-5, ES-6, and ES-7 products in particular, are presented. This is followed by brief descriptions of previous INEL product evaluation work, and of the ES-5, ES-6, and ES-7 tests. The report 
then describes the sampling and analysis strategies, methods, and results of the ES-5, ES-6, and ES-7 product study. The study examines the megascopic and microscopic properties of the samples as determined using the naked eye, planepolarized light microscope, and the electron microprobe.

\section{Product Evaluation Objectives}

The objective of the ISV product waste form characterizotion is to obtain an understanding of the nature of the vitrification process in order to predict the applicability of ISV to various waste materials. ISV may be applicable if the waste materials are adequately processed and the expected product performance is acceptable. The general strategy for the evaluation of waste forms produced during the ISV process ${ }^{1}$ includes three general tasks, (a) bulk description of the product, (b) chemical and physical property characterization, and (c) chemical durability testing.

The first task generates a megascopic description of the product and associated phases present. The description allows an assessment of the degree of processing of the waste materials and identifies the presence of product performance indicators, such as the presence of distinct metallic phases.

The second task generates an understanding of the elemental composition, structure, and distribution of the phases in the product. The distribution of waste components within the phases are identified in the second task. The data are used to further assess the degree of processing and expected product performance. For example, elemental composition influences the chemical durability of the product and the distribution of the phases present influences the mechanical, and thus the overall, durability of the product. The chemical composition and phases present also provide insight into the properties of the melt during processing. Such insights can be valuable in process control and general ISV implementation.

Chemical durability testing involves four types of leach testing for three purposes: (a) toxicity characterization leaching procedure (TCLP) to meet regulatory requirements for 1 andfill disposal, (b) MCC-1 and Product Consistency Test (PCT) to allow comparison to similar wasteforms and natural analogues, and 
(c) testing to determine the intrinsic (fastest) rate of waste form dissolution for risk assessment source term use.

Detailed strategies for accomplishing the product evaluation tasks are given in Reference 2. Megascopic and microscopic properties of the products are discussed in this document, exclusive of durability.

The ES-5, ES-6, and ES-7 product properties are determined in order to supplement the existing data base on the product that results from ISV of buried waste. Specific objectives of the study, which address the processing adequacy and product performance discussed above, are:

- Evaluate the completeness of processing of waste and waste containers.

- Characterize the product composition. Identify the phases present and the chemical composition of identified phases.

- Characterize the product homogeneity. Describe the distribution and associated microstructures of the identified phases. Describe any observed spatial variability in chemical composition.

- Describe the chemical durability of the product based on natural and test analogues.

- Describe any difference between test products studied.

\section{Previous Work}

The pilot, or intermediate-scale, tests performed at the INEL in 1990 (IFT-1 and IFT-2) were performed on simulated buried waste pits that contained metal, combustibles, and other materials. ${ }^{3}$ The products of these tests were found to be chemically homogeneous glass and crystall ine silicate materials with small amounts of metallic iron phases. Rare-earth element surrogates of transuranic elements were also found to be homogeneously distributed in the products. Heavy gauge metal containers settled in the melt, but light gauge 
metal was processed, along with wood, paper, cloth, calcium silicate sludge, scrap glass, and concrete. The chemical durability of the glass was found to be 10 times more durable than typical high-level nuclear waste borosilicate glasses on the basis of MCC -1 leach tests. ${ }^{a}$

Engineering-Scale Test 4 (ES-4) was conducted on INEL soil with added TCLP toxic metals, an organic siudge mixture, combustible materials, and steels. ${ }^{4}$ The soil mixture was placed above a block of basalt to simulate the INEL geologic setting. The product consisted of coexisting vitreous, crystalline, and metallic phases. ${ }^{5}$ Two silicate liquids were generated, one from soil and one from basalt, and the liquids did not mix appreciably. Metal scrap articles accusulated at the bottom of the melt with melted metal. Metallic phases also occurred in the glass as round inclusions several micrometers in size. The major element composition of the glass was relatively homogenous. TCLP toxic metals were retained in the glass and associated with iron metallic phases. ES-4 glass samples did not exceed TCLP thresholds, but TCLP results for the product as a whole were inconclusive. The chemical durability of ES-4 glass, based on limited MCC-1 leach testing, was also found to be 10 times that of typical high-level nuclear waste glasses.

\section{Test Descriptions}

\section{Test Objectives and Designs}

ES-5. ES-5 test objectives and design are given in Reference 6 . The test objectives focused on the behavior of sealed containers containing a composite mixture of sludge during vitrification. The sludge composite simulated waste found at the INEL SDA, which is an area that may be remediated using ISV. The sludge contained a variety of materials, including hazardous organic materials, petroleum products, nitrates, calcium silicate, and mercuric and other inorganic oxides. The sludge composite was modified into four series that were spiked with different chemical tracers and spatially arranged to accomplish specific objectives. Two hundred $5 \mathrm{~cm}(2 \mathrm{in.})$ diameter and $7.5 \mathrm{~cm}(3 \mathrm{in}$.$) tall carbon$ steel containers were placed horizontally in a single layer in the soil to be

a. Tests performed for 28 days at $90^{\circ} \mathrm{C}$. 
vitrified. The containers were scaled 1:12 to simulate drums that would be processed with large-scale equipment with an electrode separation of $3.66 \mathrm{~m}$ $(12 \mathrm{ft})$. The compositions of the sludge series placed in the containers are given in Table 1. INEL soil was used in the test; Table 2 gives the soil compositions measured for previous ISV tests (see References 3, 7, 8, and 9).

ES-6. ES-6 test objectives and design are given in Reference 10. The test objectives were to determine the effects of ISV on containerized sludge buried in a random array to sim: 17 ate random drum disposal. The sludge composition used in the carbon steel containers was much the same as in ES-5; Table 3 gives the components of the sludge. The $5 \mathrm{~cm}(2 \mathrm{in.}$, diameter and $7.5 \mathrm{~cm}(3 \mathrm{in}$.$) tall$ containers were $\mathrm{placed}$ in three arrays containing 13 containers, each at different depths, in the $416 \mathrm{~L}$ (110 gal) drum used for the test.

ES-7. Reference 11 describes the test objectives and design for ES-7. The objective of ES-7 was to examine the effects of ISV on containerized sludge of varying content. In ES-7, only three containers were used, upright in different vertical positions in the zone to be vitrified; two of the containers were filled with the sludge mixture and the third was filled with Regal 011 . The same size and type of containers as in ES-5 and ES-6 were used.

\section{Test Operations and Results}

ES-5 was performed at PNL using enyineering-scale equipment with an electrode separation of $30 \mathrm{~cm}(12 \mathrm{in.})$ and was conducted in a $1.83 \mathrm{~m}(6 \mathrm{ft})$ diameter container. The test was run at one-twel fth the scale of large scale, which has an electrode spacing of approximately $3.66 \mathrm{~m}(12 \mathrm{ft})$. ES-6 and ES-7 were performed by Geosafe Corporation using a slightly different test setup; Geosafe Corporation used a $20.3 \mathrm{~cm}$ ( 8 in.) electrode separation and performed the tests in a $416 \mathrm{~L}$ (110 gal) drum.

Unpublished status reports prepared by Geosafe recorded the maximum temperatures in the me $1 \mathrm{t}$ as $1516^{\circ} \mathrm{C}$ for ES-6 and $1914^{\circ} \mathrm{C}$ for ES-7. No melt temperatures were available for ES-5. 
Table 1. Compositions of sludge series used in ES-5 $5^{\mathrm{a}}$ in wt\%.

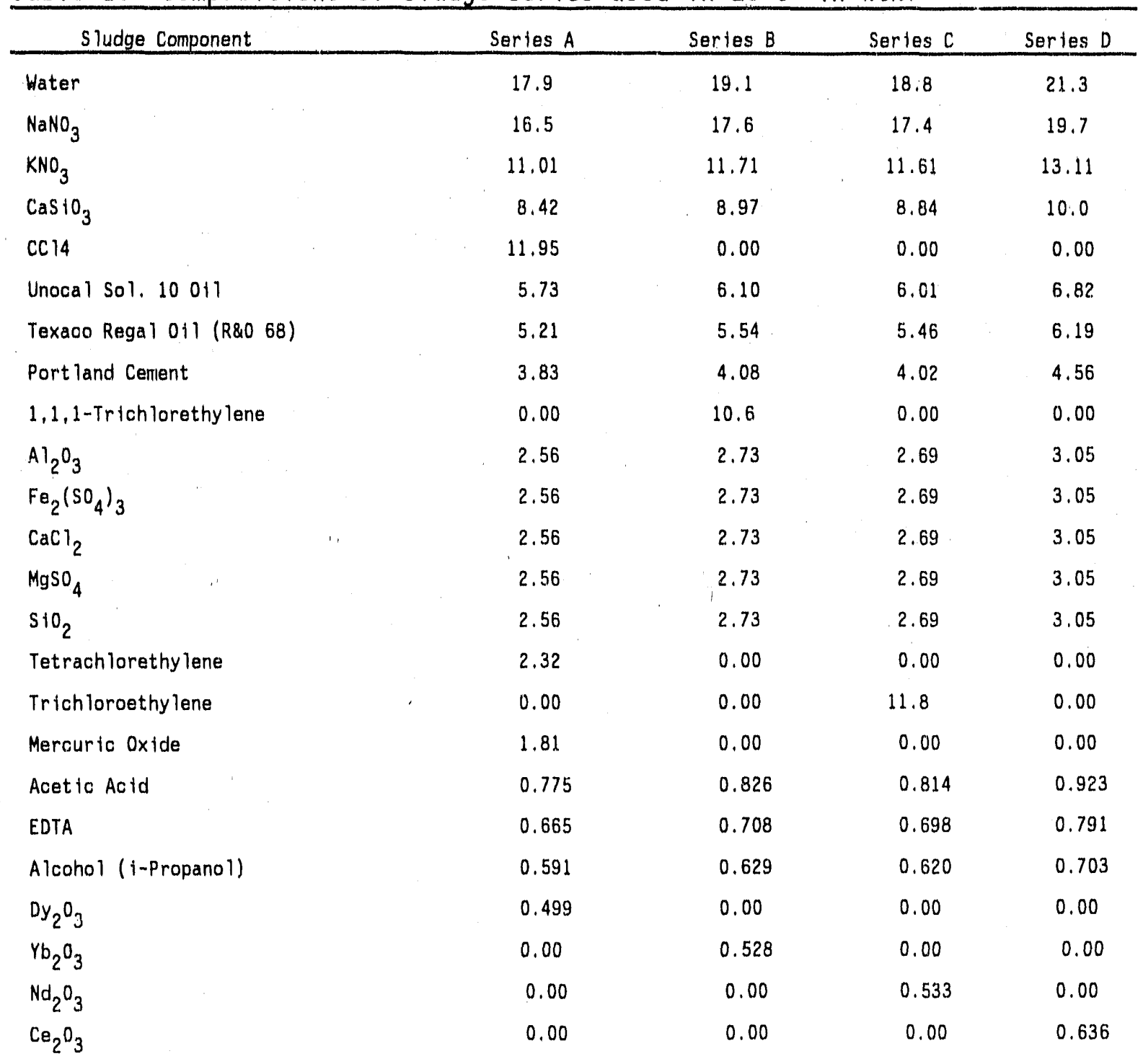

a. Private communication with R. K. Farnsworth, EG\&G Idaho, Inc., September 13, 1991. 


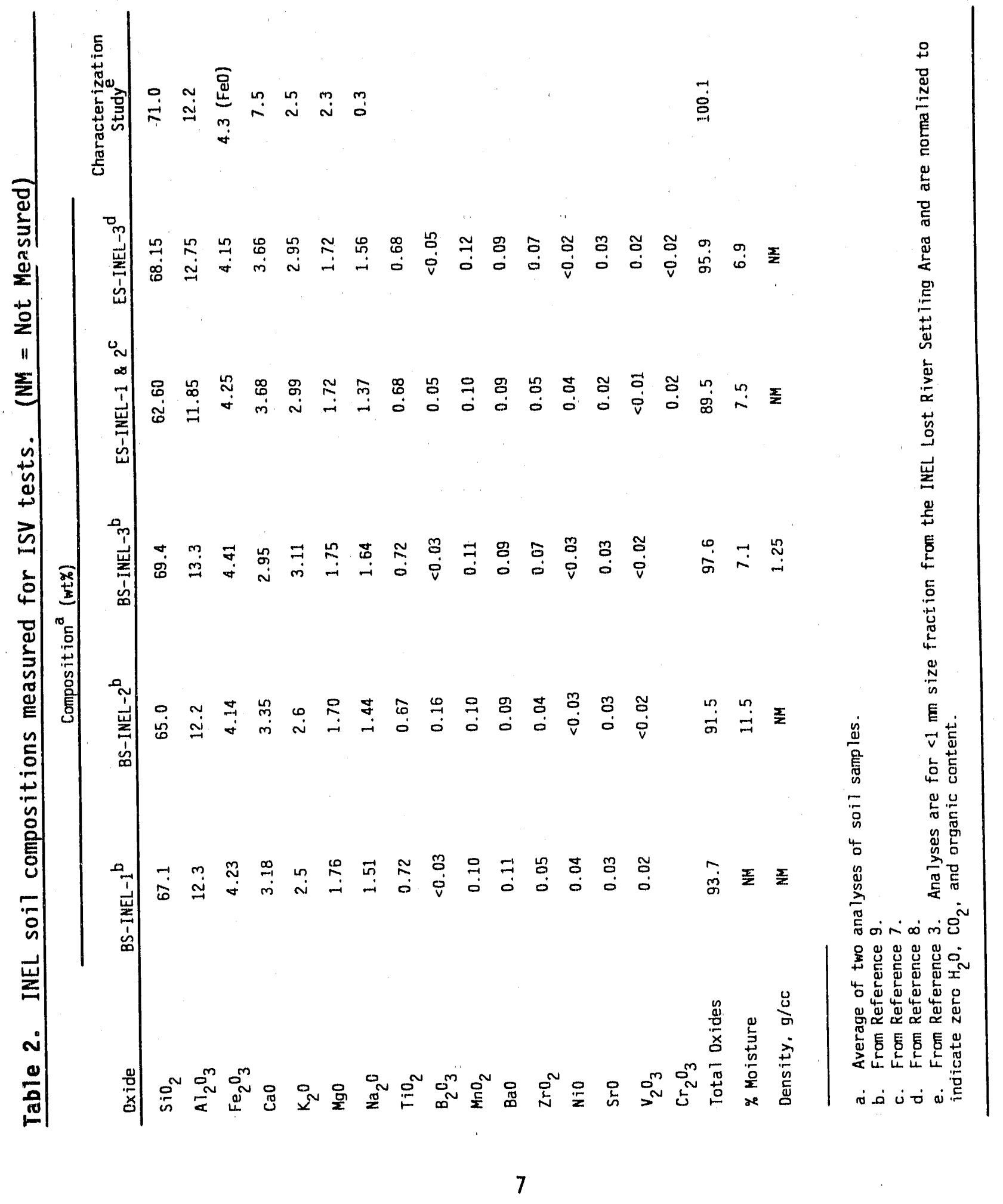


Table 3. Composition of sludge used in ES-6 and ES-7. (From References 10 and 11)

\begin{tabular}{lc}
\hline \multicolumn{1}{c}{ Material } & wt\% \\
\hline Water & 18.05 \\
Rare Earth Oxide (CEO & 0.54 \\
$\mathrm{Fe}_{2}\left(\mathrm{SO}_{4}\right)_{3}$ & 2.58 \\
$\mathrm{CaCl}_{2}$ & 2.58 \\
$\mathrm{MgSO}_{4}$ & 2.58 \\
$\mathrm{Al}_{2} \mathrm{O}_{3}$ & 2.58 \\
$\mathrm{SiO}_{2}$ & 2.58 \\
Mercuric Oxide & 1.82 \\
Calcium Silicate & 8.47 \\
Texaco Regal Cil & 5.24 \\
Carbon Tetrachloride & 6.30 \\
Trichloroethane & 2.80 \\
UnoCal Soluble 10 0i1 & 5.76 \\
Trichloroethylene & 2.33 \\
Alcohol (Isopropanol) & 0.60 \\
Organic Acid (Acetic Acid) & 0.78 \\
EDTA & 0.67 \\
Sodium Nitrate & 16.66 \\
Potassium Nitrate & 11.11 \\
Portland Cement & 3.86 \\
TOTAL & 100.00 \\
\hline
\end{tabular}




\section{PHYSICAL AND CHEMICAL PROPERTY CHARACTERIZATION}

\section{Sampling and Analysis Strategy}

The sampling of the ES-5, ES-6, and ES-7 products occurred in several episodes. The sampling conducted by. PNL and Geosafe to support general test evaluation is not discussed here. Sampling of the ES-5 product was performed when the block was intact; however, ES-6 and ES-7 product samples were collected from broken block pieces. The ES- 6 and ES-7 broken block pieces were shipped to the INEL by Geosafe Corporation in two cardboard barrels, one labeled ES-7 and one labeled ES-6. Inside the barrel labeled ES-6, three torn plastic bags were found; one of the bags was labeled "Test 7 Cold Cap." A second bag also appeared to have cold cap material in it; this material was assumed $t_{0}$ be from the ES- 6 cold cap. There was significantly more material attributed to ES-6 than to ES-7. Unpublished status reports prepared by Geosafe indicate the reverse; ES- 6 is reported as weighing $45.5 \mathrm{~kg}(100 \mathrm{lb})$ and ES-7 is reported as weighing $77.3 \mathrm{~kg}$ (170 1b). Although the potential for sample mixup was minimized by sampling material from bags rather than from material that had fallen out of the bags, there remain questions regarding the identification integrity of the samples of both tests. The samples received more limited analysis than originally planned and were evaluated in a composite, as opposed to a comparative, manner.

Sampling and analysis guidelines followed for the product evaluation are provided in Reference 2. Sampling strategies for chemical and physical property characterization of the available material are given below.

\section{Megascopic Description}

Samples from each of the ES-5, ES-6, and ES-7 products were collected for study and analysis. The samples were chosen so that one or more examples of each megascopically distinguishable morphology was represented in the sample collection. Where possible, samples were selected that contained two or more features so that the relationships among them could be established. The sampling of the products from each of the tests is described in the following paragraphs. 
ES-5. Prior to sampling, the following observations on the ES-5 product were made. The top surface of the ES-5 block appeared slag-like with a subsidence hole in the center of the block. The block appeared to be in two parts. The upper part was narrower than the block on the bottom. The bottom half appeared to be the actual monolith. The upper portion appeared to be a partially reacted surface which the melt penetrated before interacting with the waste. The color of the upper half was brown with a slight red tinge. The lower half was gray. The upper surface of the bottom-half peripheral to the upper-half peripheral was a darker gray with black particles of what appeared to be graphite or charcoal. Some cans were attached to the monolith, most at the top of the lower half. All cans were broken, melted, and/or breached. Calcium silicate or a dark material could be seen within the cans. ${ }^{b}$

Six samples were collected and analyzed from the ES-5 product block. Two samples were collected from the top center of the product block, one from the cold cap subsidence area, one from the center, and two from the vertical center near an electrode. The primary features observed megascopically in the samples were green-colored glass, vesiculated (exhibiting bubbles) rind, and metal beads up to about $3 \mathrm{~mm}$ in diameter. The rind was gray, fine-grained sintered material at the contact between glass and soil. Figure 1 shows sample IC201A90E5 glass and rind. Figure 2 shows the contact soil in the same sample. The glass commonly contains about 1 percent by volume (vol\%) microscopic to $7 \mathrm{~mm}$ diameter vesicles (a few samples have vesicles with diameters in the tens of $\mathrm{mm}$ ) and $<1$ vol\% gray subrounded particles $<1 \mathrm{~mm}$ in diameter. The gray particles were distributed irregularly throughout the glass; in some samples, the particles were present in a swirled pattern. The glass contained irregular rectangular inclusions of the rind material in several samples. Electrode contact surfaces were magnetic and exhibited graphite coating in places.

ES.6. The broken and random nature of the product at the time of the sampling prevented sampling from precise locations within the undisturbed product. However, based on the features observed in the sample, some estimation

b. Source of sampling information for ES-5 are the ERP-170-90 sample logbook entries made by $S$. 0. Bates, EG\&G Idaho, Inc., Idaho Falls, Idaho, November 5, 1990. 


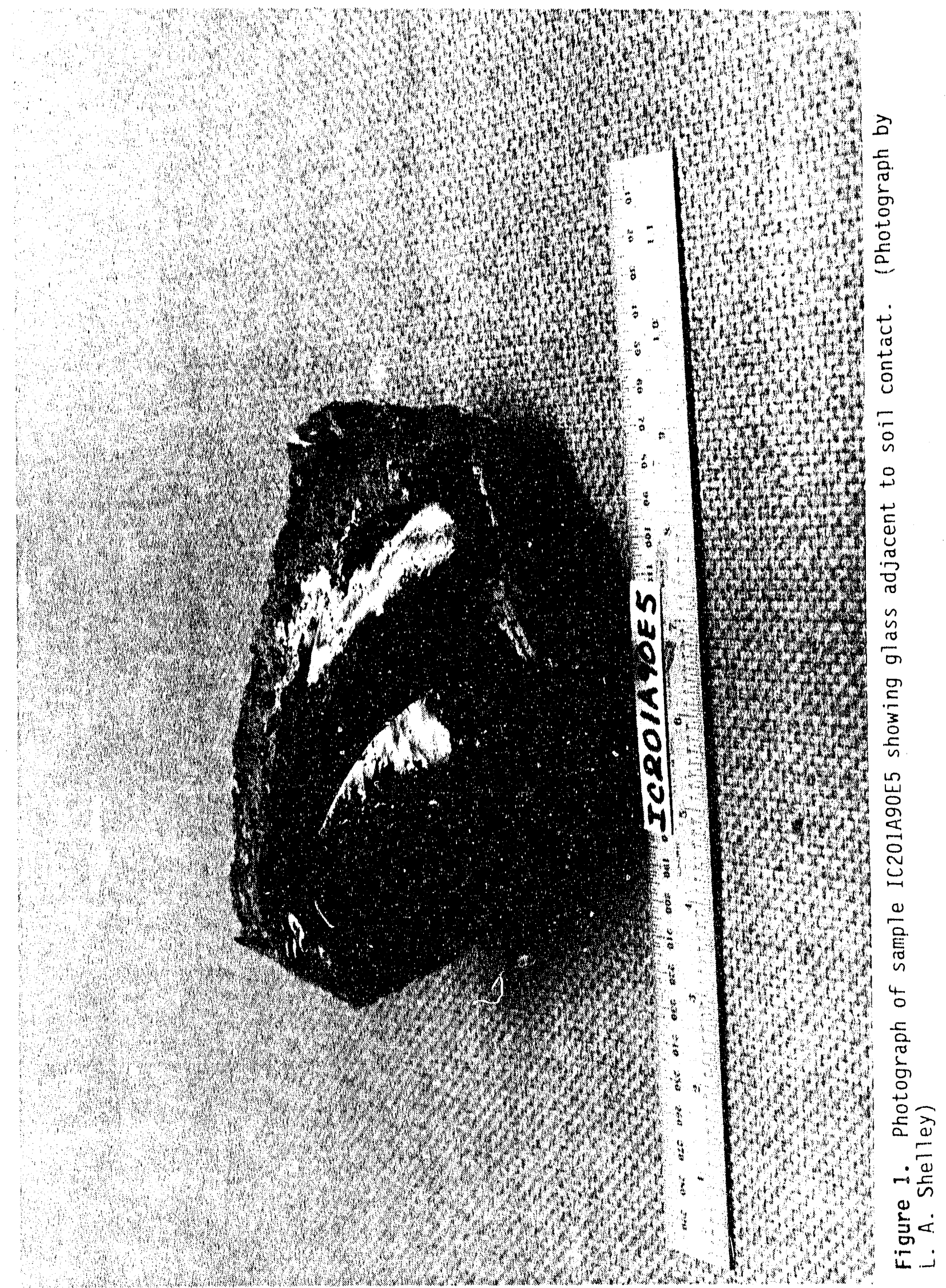




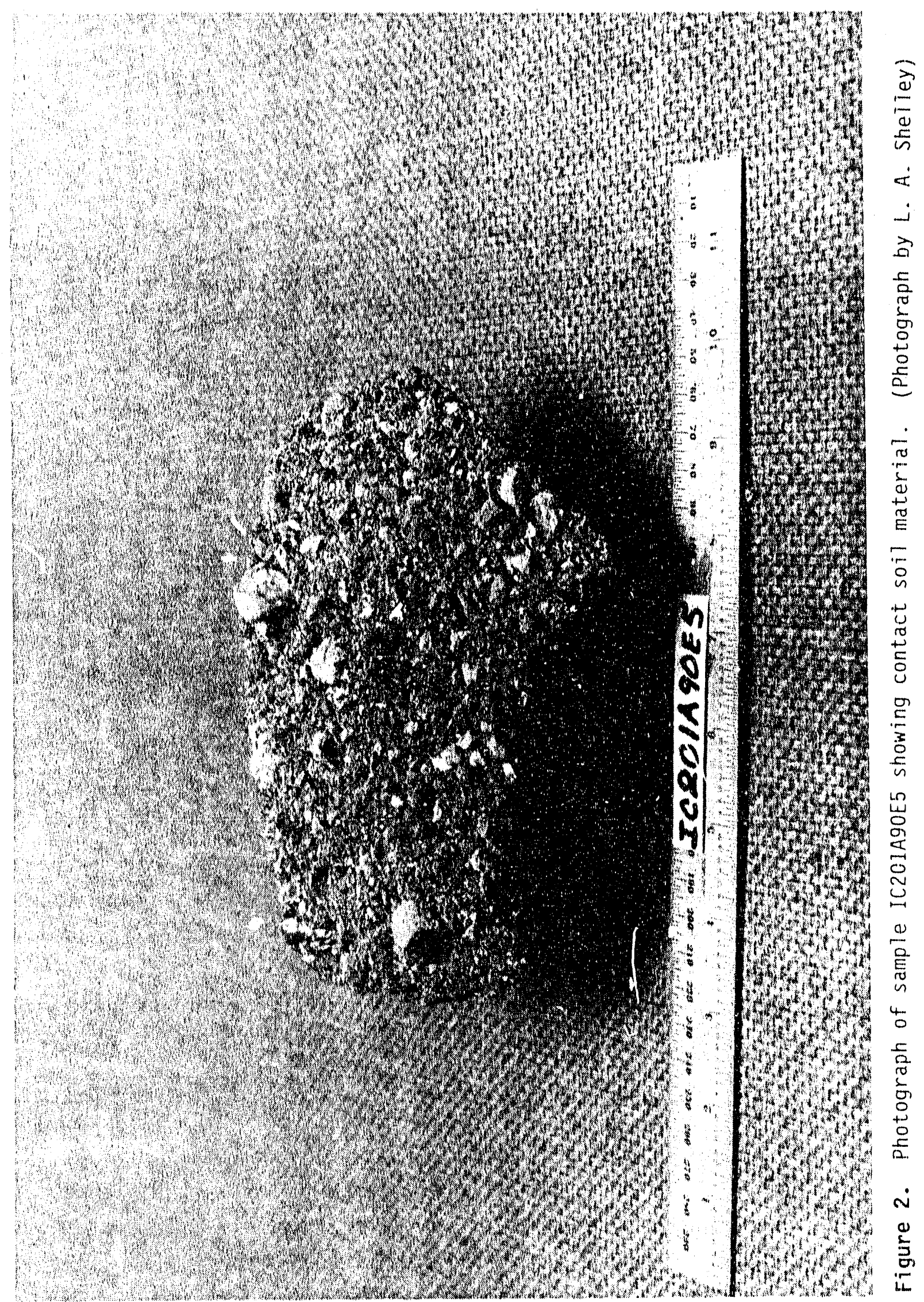


of sample location was possible. The presence of contact sol1, electrode imprints, and cold cap characteristics were helpful in identifying probable sample locations. In addition, the amount of vesicles in the glass was indicative of the vertical sample location.

The location of three samples analyzed from ES-6, based on indicative megascopic sample features, were the top portion of the blrck including edge material and the approximate vertical center between electrodes and sofl. Figure 3 shows a photograph of material between an electrode and the soil contact (sample IC501A90E6). The features observed in ES-6 were much the same as those observed in the ES-5 product; however, the glass was greenish-brown or black in color and a few gray particles were noted. A large gas bubble, at least $100 \mathrm{~mm}$ in diameter, was observed in sample IC503A90E6 ${ }^{\circ}$ (see Figure 4); this type of feature was also observed in ES-5.

ES-7. Like the ES-6 product, the ES-7 product was broken at the time of sampling and sample locations were inferred from the features observed in the sample. Two samples were believed to have come from the center or upper center of the product block, three from the top portion, one from the cold cap, and one from the bottom under an electrode. All samples had a soil contact included. The features observed in ES-7 were mostly the same as those observed in the ES-6 product.

\section{Microscopic Properties}

Chemical and physical properties of ES-5, ES-6, and ES-7 were measured using plane-polarized light microscopy and the electron microprobe. Index of refraction measurements and examination of petrographic polished thin sections provided information about the mineralogic composition and microscopic features of the product. Electron microprobe analysis provided insight into the composition and interrelationships of specific phases present.

Samples from the top portion and the center and/or bottom section of the product blocks from each of the tests were examined. Generally, two or more

c. Sample not analyzed and, thus, not described in this report. Sample was probably from the center of the product. 


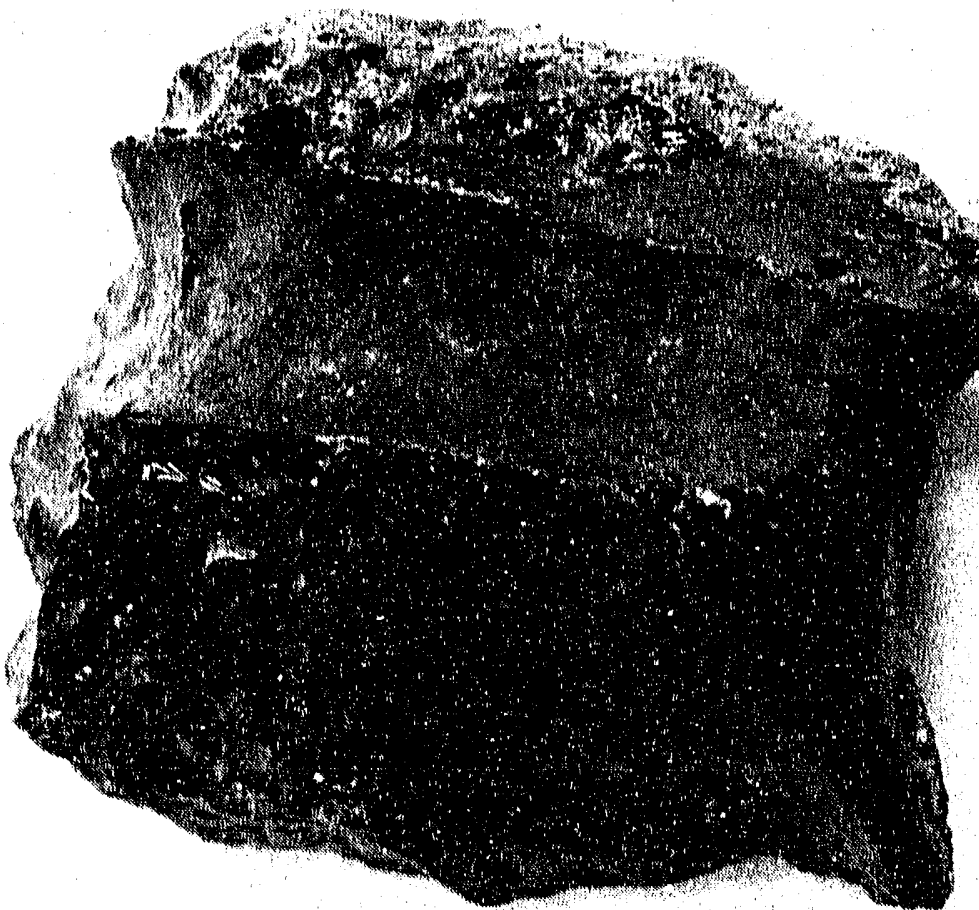

y

бo

.

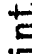

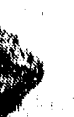

$\infty$

4

के
4

$6^{-}$

0

4

4

8

as.

$4 n_{x}$

3

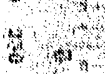

4

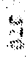

$+$

章

穿市

号水

동

远

뜽 흥

唋宁

is

4 응

듬

它通

옹 은

先

m

结皆

严嵒 


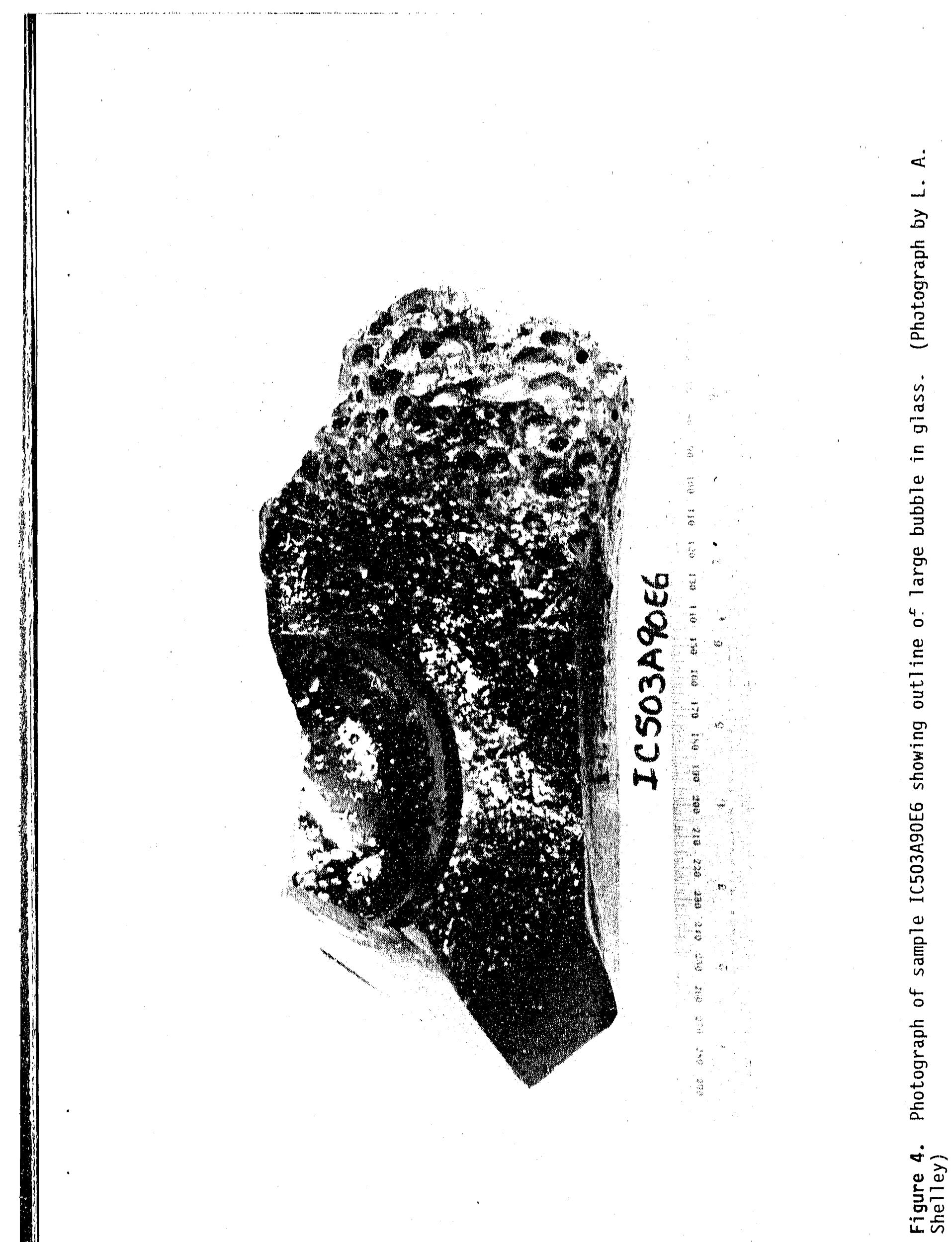


phases or characteristics were exhibited in each sample; thus, subsamples were prepared based on the features observed and submitted for analysis as indicated in Table 4. Subsamples are identified with letters B, C, etc. in the sixth position in the sample number. A brief description of the samples examined, sample locations, and subsample characteristics are given in the hand-specimen description section below.

Index of refraction was measured on 5 subsamples, 19 subsamples were examined in thin section, and 10 of the latter subsamples were examined using the electron microprobe. A blind quality control sample was submitted for electron microprobe analysis.

\section{Analysis Techniques}

Samples were submitted for analysis under chain of custody. Analysis methods for chemical and physical property characterization and for chemical durability testing are given in Reference 2. The methods, analysts (where different from the authors), and data validation results are given in following sections.

\section{Microscopic Properties}

Plane Polarized Light Microscopy. Index of refraction was measured on five powdered subsamples using the Becke line method for determining index of refraction. An 0lympus $\mathrm{BH}$ plane-polarized light microscope and refraction oils from Cargill Laboratories were used for the analysis. Nine subsamples were examined in polished thin section using a Leitz Dialux-Pol plane-polarized light microscope. Ten other subsamples were examined in polished thin section in conjunction with electron microprobe analysis.

Electron Microprobe. Microchemical analyses of 10 subsamples were carried out at the Idaho Geologic Survey/Comer Laboratories electron microprobe laboratory at the University of Idaho using an ARL-EMX electron microprobe operated at $15 \mathrm{KV}$ and 0.1 microamp beam current. The analyses were performed on polished thin sections using standard operating procedures. Data derived from the electron microprobe examinations were of three types: (a) photomicrographs of micro- 
Table 4. Analyses performed on subsamples.

\begin{tabular}{|c|c|c|c|c|}
\hline Test & Subsample & $\begin{array}{r}\text { Index of } \\
\text { Refraction }\end{array}$ & $\begin{array}{l}\text { Thin Section } \\
\text { Examination }\end{array}$ & $\begin{array}{l}\text { Electron } \\
\text { Microprobe }\end{array}$ \\
\hline 5 & IC200B90E5 & -. & $Y$ & - - \\
\hline 5 & IC201B90E5 & - & 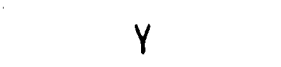 & $\ldots$ \\
\hline 5 & IC203B90E5 & Y & $Y$ & $Y$ \\
\hline 5 & IC204B90E5 & - & $\gamma$ & -. \\
\hline 5 & IC207B90E5 & $\ldots$ & Y & - \\
\hline 5 & IC208B90E5 & $Y$ & $Y$ & $Y$ \\
\hline 6 & IC501B90E6 & - & $y$ & $Y$ \\
\hline 6 & IC501E90E6 & $\ldots$ & Y & $Y$ \\
\hline 6 & IC502B90E6 & $\cdots$ & $Y$ & $Y$ \\
\hline 6 & IC502D90E6 & - & $Y$ & $Y$ \\
\hline 6 & IC504C90E6 & $-\cdots$ & Y & - \\
\hline 7 & IC402B90E7 & - & $Y$ & -- \\
\hline 7 & IC402C90E7 & $\cdots$ & $Y$ & - \\
\hline 7 & IC403B90E7 & $Y$ & - & -- \\
\hline 7 & IC404B90E7 & -. & $Y$ & Y \\
\hline 7 & IC404C90E7 & $Y$ & - & -- \\
\hline 7 & IC405C90E7 & - & $Y$ & -. \\
\hline 7 & IC405D90E7 & - & $Y$ & $Y$ \\
\hline 7 & IC406C90E7 & - & Y & Y \\
\hline 7 & IC4.08B90E7 & - & $\gamma$ & Y \\
\hline 7 & IC409B90E7 & $Y$ & $Y$ & $\ldots$ \\
\hline
\end{tabular}


structural features, (b) energy dispersive $x$-ray spectrometry (EDS) determinations of elemental compositions of phases, and (c) $x$-ray maps showing elemental distribution within microstructural features. Photomicrographs were made of representative areas of each sample using backscattered electron (BSE) imaging. The analyses reported were performed using five well-characterized mineral standards; each analysis datum is the mean of about twenty individual measurements.

Several measures were available to assess the quality of the electron microprobe analyses: (a) standard deviation estimates, (b) blind control samples, and (c) oxide sums. The reported standard deviation of each oxide value ranged from a worst case $5.7 \mathrm{wt} \%$ for $\mathrm{SiO}_{2}$ to 0.01 wt\% for $\mathrm{P}_{2} \mathrm{O}_{5}$. (Standard deviations are presented with the data in Table 7.) A blind control sample that had been analyzed by the same laboratory on a previous occasion was submitted with the samples for analysis. Table 5 gives the control simple analysis results, which are in good agreement considering analysis and subsample variabilities. In addition, a blind analysis of three National Institute of Standards and Technology (NIST) glass standards was carried out by the same laboratory and analyst. The agreement between the oxide values measured and the published values is excellent. Finally, a reasonable test of the reliability of the data is that the sum of the major elements oxides of an acceptable analysis will be $100 \pm 5$ weight percent $(w t \%)$. These analyses meet this requirement; the reported sums vary from $96.2 \mathrm{wt} \%$ to $103.6 \mathrm{wt} \%$.

\section{Analysis Results and Discussion}

\section{Hand Specimen Descriptions}

This section presents a discussion of the megascopic properties of each of the samples examined in this report, together with an estimate of the sample's position in the original waste form, if possible. ${ }^{d}$

ES-5. The following are hand specimen descriptions of ES-5 samples.

d. Descriptions for ES-6 and ES-7 are modified from detailed descriptions done by L. A. Shelley, EG\&G Idaho, Inc., Idaho Falls, Idaho. 
Table 5. Quantitative electron microprobe analyses for subsamples of sample IC007A90IE performed by Idaho Geological Survey. Analyses are reported in wt\%.

\begin{tabular}{lcc} 
Subsample & ICO07B90IE & ICO07C90IE \\
\hline $\mathrm{Al}_{2} \mathrm{O}_{3}$ & 12.10 & 12.10 \\
$\mathrm{CaO}$ & 12.90 & 12.30 \\
$\mathrm{Fe} 0$ & 4.00 & 4.20 \\
$\mathrm{~K}_{2} \mathrm{O}$ & 1.40 & 2.70 \\
$\mathrm{MgO}$ & 2.80 & 2.80 \\
$\mathrm{Na}_{2} \mathrm{O}$ & 2.60 & 1.20 \\
$\mathrm{SiO}_{2}$ & 65.90 & 62.70 \\
$\mathrm{TiO}_{2}$ & 0.71 & 0.52 \\
$\mathrm{P}_{2} \mathrm{O}_{5}$ & 0.26 & 0.20 \\
$\mathrm{Sum}$ & 102.67 & 98.72 \\
\hline
\end{tabular}


IC200A90E5-This sample contains gray, somewhat friable soil material in contact with gray vesiculated rind in contact with glass, which shows an electrode contact. The sample is from the edge of the cold cap area. The rind is 10 to over $30 \mathrm{~mm}$ thick and contains $25-30 \%$ vesicles that grade from microscopic to approximately $5 \mathrm{~mm}$ in diameter towards the glass. In several areas where the variegated gray rind interfaces with the glass, thero is a glassy green/gray material with texture similar to the gray rind. The glass is shiny green with 15-20\% vesicles that range from 3 by $6 \mathrm{~mm}$ up to tens of $\mathrm{mm}$ in size. Some areas of the glass have light-gray inclusions either in a swirly feature or as angular particles <1 $\mathrm{mm}$ in size. The electrode contact is graphite coated and is $57 \mathrm{~mm}$ long and $27 \mathrm{~mm}$ wide. Subsample IC200B90E5 contains the soil contact, glass, and electrode imprint.

IC201A90E5-This sample is a massive glass sample which contains a soil contact and vesiculated rind. The sample is from the center portion of the monolith near an electrode. The sample also contains a cast of an electrode, which has a gray magnetic surface. The rind is 12 to $15 \mathrm{~mm}$ thick and contains $25-30 \%$ vesicles that grade from microscopic to $5 \mathrm{~mm}$ in diameter towards the glass, with which the rind forms an irregular contact. The rind/glass interface contains three strongly magnetic metal beads approximately $5 \mathrm{~mm}$ in diameter. In several areas, where the gray rind makes contact with the glass, there is a glassy-grayish material with texture similar to the gray rind. The glass is shiny-green with $<1 \%$ vesicles that are $<1 \mathrm{~mm}$ size; a few 1 arger $(6-8 \mathrm{~mm})$ vesicles are present. In some areas of the glass near the rind, the glass contains rindlike inclusions. The inclusions are 1-2 mm wide, up to approximately $25 \mathrm{~mm}$ long, and are irregularly shaped. The glass also contains 2 strongly magnetic metal beads approximately $3 \mathrm{~mm}$ in diameter. Subsample IC201B90E5 contains the soil contact, glass, and electrode imprint.

IC203A90E5-This sampie is composed of four pieces of massive greenshiny glass. One of the pieces exhibits a gray electrode contact surface, which is magnetic. The sample is from the vertical center of the monolith at one of the electrodes. Glass contains < $1 \%$ vesicles that are microscopic except for several that are $<1 \mathrm{~mm}$ and one that is $3 \mathrm{~mm}$ in size. Subsample IC203B90E5 is a sample of the glass. 
IC204A90E5-This sample is composed of massive green-shiny glass from the vertical and horizontal center of the monolith. The sample contains an irregularly shaped magnetic metallic-gray area 95 by $53 \mathrm{~mm}$ with approximately $15 \%$ vesicles that range from 3 to $12 \mathrm{~mm}$ in size. The area contains approximately $3 \%$ strongly magnetic metal beads that are 3-5 mm in diameter and finely vesiculated lighter-colored material near the outer edges. The glass contains $<1 \%$ vesicles that range from microscopic to $17 \mathrm{~mm}$ in diameter and approximately $1 \%$ strongly magnetic metal beads that range from $<1$ to $3 \mathrm{~mm}$ in size. The glass also contains areas of lighter-gray particles of sizes $<1 \mathrm{~mm}$ in a linear patterns $1-3 \mathrm{~mm}$ wide and tens of $\mathrm{mm}$ long; the patterns appear to have a higher percentage of vesicles. One $1 \mathrm{~mm}$ white subrounded particle was observed. Subsample IC204B90E5 includes the gray particles and material from the irregular metallic gray inclusion.

IC207A90E5-This sample is green glass from the top portion of the monolith near the (horizontal) center with vesicles somewhat gradational from $2 \%$ smaller vesicles to $10-15 \%$ larger vesicles. Vesicles are microscoptc to $9 \mathrm{~mm}$ in diameter. The glass contains $1-2 \%$ metal beads ranging from microscopic to $3 \mathrm{~mm}$ in diameter. The area with the larger vesicles contains a carbonaceous inclusion that is 7 by $7 \mathrm{~mm}$; it also contains a $1 \mathrm{~mm}$ wide by $21 \mathrm{~mm}$ long white inclusion, which contains dark fine (not visible to naked eye) lineations. Medium-gray particles/crystals, $<1 \mathrm{~mm}$ in size, are present in one area of the $\mathrm{glass}$ in concentrations up to $40-50 \%$. Other nonglassy areas are present; one near the carbonaceous material and one with the gray particle/crystal concentration. The nonglassy areas have dimensions $5-10 \mathrm{~mm}$ and are more finely vesiculated than the surrounding glass. Subsample IC207B90E5 is glass with gray particles included.

IC208A90E5-This sample is green glass from the top portion of the monolith near the (horizontal) center with $1 \%$ vesicles ranging from microscopic to $4 \mathrm{~mm}$ in diameter. The glass contains several metal beads that range from $<1$ $\mathrm{mm}$ to $4 \mathrm{~mm}$ in diameter. The glass also contains < $1 \%$ gray particles/crystals subrounded in shape and $<0.5 \mathrm{~mm}$ in diameter that are somewhat uneveniy distributed throughout the glass. Subsample IC208B90E5 is glass with gray particles included.

ES-6. The following are hand specimen descriptions of ES-6 samples. 
IC501A90E6-This sample is highly vesicular glass with soll and electrode contacts. The sample is probably from the top portion of the product, at the edge. The sample includes rind which serves as the inner wall above the subsided glass and outer glass/soil interface on the side of the sample. The rind is typically 8 to $12 \mathrm{~mm}$ thick and is gray in color. The smaller gas bubbles are toward the outside edge of rind and grade larger toward the glass. Larger bubble sizes in the rind are up to $6 \mathrm{~mm}$. The top of the sample has highly vesicular glass with approximately $60 \%$ gas bubbles ranging in size from $33 \mathrm{~mm}$ to microscopic. The subsidence surface has rust-colored glass with light tan or brown swirls in it. Gas bubble size and quantity decrease to massive glass with $1 \%$ gas bubbles <1 mm in diameter at the base of the sample. The glass is greenish-black; at the elecirode imprint flecks of flake graphite are observed on the glass. Subsample IC501B90E6 contains the soil and electrode contacts. Subsample IC501E90E6 is from the massive glass at the base of the sample, between the electrode imprint and the soil contact. The subsample was divided into a rind portion (labeled IC501B90E6 Rind) and a glass portion that included the electrode contact (1abeled IC501B90E6 Glass) for electron microprobe analysis.

IC502A90E6-This sample is from the top portion of the melt with subsidence area and cold cap, vesicular glass, and massive glass toward the bottom of the sample. The sample also includes an electrode imprint and scil contact, a portion of which is in contact with a subsidence surface. The glass is greenish-black. The rind is finely vesiculated glass; above the subsided glass the rind is typically 10 to $16 \mathrm{~mm}$ thick and gray in color. Gas bubbles in rind grade from $6 \mathrm{~mm}$ to $<1 \mathrm{~mm}$ in diameter, from the outside edge getting smaller toward the glass. The glass at the top of the sample is highly vesicular with varying sizes of gas bubbles ranging in size from $45 \mathrm{~mm}$ to microscopic. Vesicles make up approximately $70 \%$ of the surface. The top surface has dark-green (black) and rust-colored glass with light tan or brown areas swirled in it. Gas bubble size and proportions decrease down the sample; at the bottom, glass is massive with approximately $1 \%$ gas bubbles $<1 \mathrm{~mm}$ in size. There is a gas bubble at the bottom of this sample that is very large. The portion of the cavity present is $>60 \mathrm{~mm}$ high and $>65 \mathrm{~mm}$ wide. Two metallic beads are also visible. The glass at the electrode contact is black and contains flecks of flake graphite. Subsample IC502B90E6 contains the soil contact and the electrode imprint. For electron microprobe analysis, the subsample was divided into a rind portion (labeled 
IC502B90E6 Rind) and a glass portion that included the electrode contact (1abeled IC502B90E6 Glass). Subsample. IC502D90E6 is from the massive glass at the base of the sample.

IC504A90E6-This sample is massive greentsh-black glass which has a nonmagnetic thermocouple protruding through glass/soil interface and attached soil. There is a copper globule of metal from a thermocouple on soil/glass contact. The sample also has an electrode/glass imprint. The sample is probably from the edge of the product near the center or bottom. Gas bubbles are $<1 \mathrm{~mm}$ in diameter and make up $<1 \%$ of the sample, except for approximately five gas bubbles in the massive glass that are 4 to $7 \mathrm{~mm}$ in diameter. The rind is vesiculated glass which contains $5 \mathrm{~mm}$ diameter bubbles which become microscopic toward the glass. The rind is 8 to $10 \mathrm{~mm}$ thick. There is a nonmagnetic copperlike globule of metal, on the soil/glass interface. The electrode imprint in the glass is black with round indents where metal may have collected on the electrode, and metallic, magnetic circles in the glass, where metal is included in the glass. Subsample IC504C90E6 is massive glass from the sample.

ES-7. The following are hand specimen descriptions of ES-7 samples.

IC402A90E7-This is a large glass sample with sot1/glass interface, electrode/glass interface, and an electrode. The sample probably comes from the top edge of the product. The glass sample has $80 \%$ vesicles on top; the bubble sizes are $30 \mathrm{~mm}$ or smaller. Vesicles increase in size toward the probable top of the sample. This vesiculated area is approximately 40 to $50 \mathrm{~mm}$ thick. Just under the highly vesicular area is a denser glass with two visible large gas bubbles; one is $105 \mathrm{~mm}$ long, $40 \mathrm{~mm}$ high, and at least $55 \mathrm{~mm}$ wide, while the other bubble is smaller. Below these gas bubbles is massive glass with bubbles $<1 \mathrm{~mm}$ in diameter and $<1 \%$ of the volume. The rind is finely vesiculated glass with bubbles of $15 \mathrm{~mm}$ in diameter or less. The rind is 7 to $15 \mathrm{~mm}$ thick and varying gray in color. There are two cans present in the rind surface. The cans are discolored and are generally black with some rusty-colored areas and are only intact and visible on or just in the rind. The can metal is magnetic and exhibits a melted edge where metal and glass intersect. Glass fills the cans. Subsample IC402B90E7 contains the soil contact and electrode imprint. Subsample 
IC402C90E7 is a vertical section of glass between the soil contact and the electrode imprint.

IC403A90E7-This sample is a graphite electrode with glass/rind cap on the bottom end. The glass/rind cap is probably on the bottom of the electrode and represents the bottom edge of the melt. The electrode has a small amount of graphite flakes on the side. The top portion of electrode is smaller in diameter than the bottom. On the bottom of electrode the cap of glass is < $8 \mathrm{~mm}$ thick and is black. The rind is black and gray vesicular glass with $60 \%$ gas bubbles $2 \mathrm{~mm}$ in diameter or smaller. The rind is approximately $7 \mathrm{~mm}$ thick. Subsample IC403B90E7 is the rind material from the base of the electrode.

IC404A90E7-This sample is comprised of three massive greenish-black glass samples with soil/glass interfaces containing cans. Samples came from the edge of the product, probably from the center or bottom. The cans are discolored and are generally black with some rusty-colored areas and are only intact and visible on or just in the rind. The can metal is magnetic and exhibits a melted edge where metal and glass intersect. Glass fills the cans. The glass is very dark-green and appears black; it contains $1 \%$ gas bubbles, $1 \mathrm{~mm}$ in size. There are a small number $(<1 \%)$ of white angular-shaped particles, approximately $1 \mathrm{~mm}$ in diameter, that look like unmelted soil. The rind has 50-60\% vesicles which are $6 \mathrm{~mm}$ in diameter or smaller. The rind is generally $8 \mathrm{~mm}$ thick but may vary $\pm 2-3 \mathrm{~mm}$. There are magnetic metal beads in the rind area that are as big as 7 $\mathrm{mm}$ in diameter. In one of the samples, there is a swirl of duli material. It is blackish-green and is visible because of its dull surface as opposed to the shiny glass; it has the same characteristics as the glass in vesicular properties. Subsample IC404B90E7 is a sample of the glass where it does not appear homogeneous. Subsample IC404C90E7 is a massive glass sample.

IC405A90E7-This sample is primarily massive greenish-black glass with outer soil interface, electrode imprint, and vesicular near the top. The sample is a lengthwise sample of monolith, excluding bottom. There is an imprint of an electrode that runs the length of the sample. Flake graphite is visible in the electrode imprint. The sample likely came from the top and center of the product, at the edge. On top of the sample, where the glass monolith has subsided, the rind is intact $30 \mathrm{~mm}$ above the glassy cap. The thickness of the 
outer wall is between 16 and $2,4 \mathrm{~mm}$. The rind is gray and vestcular; from the soll toward the glass, gas bubbles gradually increase in size from $<1 \mathrm{~mm}$ in diameter to 3 to $5 \mathrm{~mm}$. The largest gas bubble in the rind is $9 \mathrm{~mm}$ located near the glassy phase. There is an outline of the end of a can on the outside of the rind, near the top. There are two magnetic metal beads in or near the rind. Subsided glass is very vesicular with about $70 \%$ broken bubbles that are up to $30 \mathrm{~mm}$ in diameter. Gas bubbles gradually decrease in size from the sample top to the bottom. The bubbles are $3 \mathrm{~mm}$ and oblong shaped. There is a very large gas bubble that is between the descrtbed (smaller) vesicular area and above the massive glass. The gas bubble is the width of the sample and is $30 \mathrm{~mm} \mathrm{high}$ and $30 \mathrm{~mm}$ deep. Just below the large bubble, the glass has three gas bubbles that are $5 \mathrm{~mm}$ in diameter or less; but in general, gas bubbles are $<1 \mathrm{~mm}$ and $<1 \%$ of the surface in this portion of the sample. Subsample IC405C90E7 is a vertical glass section between the electrode imprint and the soil contact. Subsample IC405D90E7 is a massive glass from inside the electrode array.

IC406A90E7-This sample is two pieces of massive greenish-black glass samples with soil interface. The pieces are probably from the center or towards the bottom of the product, at the edge. The glass has small gas bubbles, the majority of which are $<1 \mathrm{~mm}$ in diameter and make up $<1 \%$ of the surfaces. There are $<1 \%$ white angular.shaped specks $(<2 \mathrm{~mm})$ that look 1 ike unmelted dirt in the glass. The rind is black and gray in color and 7 to $10 \mathrm{~mm}$ thick, with approximately $30 \%$ gas bubbles that range from $6 \mathrm{~mm}$ to $<1 \mathrm{~mm}$ in size. Subsample IC406C90E7 is a massive glass sample.

IC408A90E7-This sample is a large, massive, greenish-black glass sample with glass/soil, and glass/electrode interfaces present. The sample is probably from the top portion of the product, at the edge. The top surface of glass is vesicular, with approximately $80-90 \%$ gas bubbles ranging in size from $>70 \mathrm{~mm}$ (1argest) to approximately $18 \mathrm{~mm}$ and smaller. In the glass gas bubbles, light gray spots or crystals are incorporated in the glass that have the appearance of mold spots. There are numerous magnetic metal beads mixed with the light gray spots. Frothy-green glass covers approximately $30 \%$ of the top surface. Light-green frothy glass is vesicular with $>80 \%$ microscopic gas bubbles. There is a large bubble that is connected to the top of the electrode imprint that is just under the top glass surface. Below the glassy top, the 
glass is much less vestcular with bubbles generally $<1 \mathrm{~mm}$ in size. There are a few gas bubbles that are $3 \mathrm{~mm}$ in diameter, but they are generally in the glass next to the glass/soll interface. The glass/sotl interface is finely vesiculated gray glass and has a partial outline of a can. There are magnetic metal beads in the glassy rind area and top vesicular region. Metal beads make up approximately $2 \%$ of the surface. In the glass there is a swirl of dull material that has not mixed completely with the shiny glass that is blackish green. It has the same characteristics as the glass in vestcular properties. The electrode imprint has magnetic metal rust in it and flake graphite. Subsample IC408B90E7 is of the portion of the sample that includes glass and a coexisting dull phase.

IC409A90E7-This sample is from the cold cap, consisting of glass with a rind (glass/soil interface). The glass is highly vesicular on the subsided glassy surface; virtually $100 \%$ of the surface is vesicles. The subsided glassy surface has different characteristics; one portion of the surface is very lightgray (almost white) in color and has a powdery substance which rubs off easily. There is a light-brown or tan color in the glass that appears medium gray where there is dark glass under it. On the very top, where the rind serves as the inner wall of the subsided area, there is a large tear-shaped drop of glass with rusty-red colored cinders on it that looks like it was once part of the outer rind. The particle size and shape of the rusty-colored cinders are the same as the outer rind. The rind is vesiculated variegated gray glass that is between 5 and $20 \mathrm{~mm}$ thick. The rind is vesicular with $70 \%$ bubbles of sizes $10 \mathrm{~mm}$ in diameter and smaller; most are approximately $2 \mathrm{~mm}$ in diameter. Subsample IC409B90E7 is a glass sample.

\section{Microscopic Properties}

Index of refraction measurements are given in Table 6. Glass, with an index of refraction of approximately 1.53, was identified in all subsamples examined. In addition, crystalline phases were observed in two of the ES-7 samples.

Polished thin section observations, made using both the plane-polarized light microscope and the electron microprobe, did not differ substantially imong tests ES-5, ES-6, and ES-7. Appendix A contains detalled descriptions of 
Table 6. Index of refraction results.

\begin{tabular}{lll}
\hline Test & Subsample & \multicolumn{1}{c}{ Index } \\
\hline 5 & IC203B90E5 & $1.527 \pm 0.001$ \\
5 & IC208B90E5 & $1.529 \pm 0.001$ \\
7 & IC403B90E7 & $1.533 \pm 0.001$ (glass) \\
& & $>1.53 \frac{4}{\text { (crystailine phase) }}$ \\
7 & IC404C90E7 & quartz \\
7 & IC406C90E7 & $1.533 \pm 0.001$ \\
7 & IC409B90E7 & $1.533 \pm 0.001$ \\
& & $1.525 \pm 0.001$ (giass)
\end{tabular}

qualitative election microprobe analysis of the samples. A summary of a 11 qualitative and quantitative observations is provided in the following paragraphs.

The rind is made up primarily of quartz, dendritic crystalline material, and vesicles. A minor amount of plagioclase was also identified in the rind. Based on previous work, the dendrites are probably clinopyroxene (See References 3 and 5.) Figure 5 shows photomicrographs of the rind in subsample IC502B90E6. The dendrites tend to surround areas of quartz, suggesting that the dendrites form from silica defictent melt during the cooling process. The melt is suggested to be "silica deficient" because the quartz had not been completely dissolved when the experiment was terminated and the melt allowed to cool. Such a composition would be deficient in the glass forming component, silica, and would be more likely to crystallize than similar material having a greater silica content. Microchemical analysis show that the dendritic crystallites have variable chemical composition (see ranges for dendrites in Table 7) and indicate that they are probably clinopyroxene. Metallic inclusions are also present in the glass near the rind material. Microchemical analysis (see Table 8 ) indicates that they are composed primarily of tron and phosphorous with some nickel. Trace amounts of arsentc were observed in one inclusion.

Glass sample thin sections typically exhibit "swirly" areas of darker material. Figure 6 shows this feature; it is visible to the naked eye. The swirl compositions were of several types. Many of the swirls, which had a 


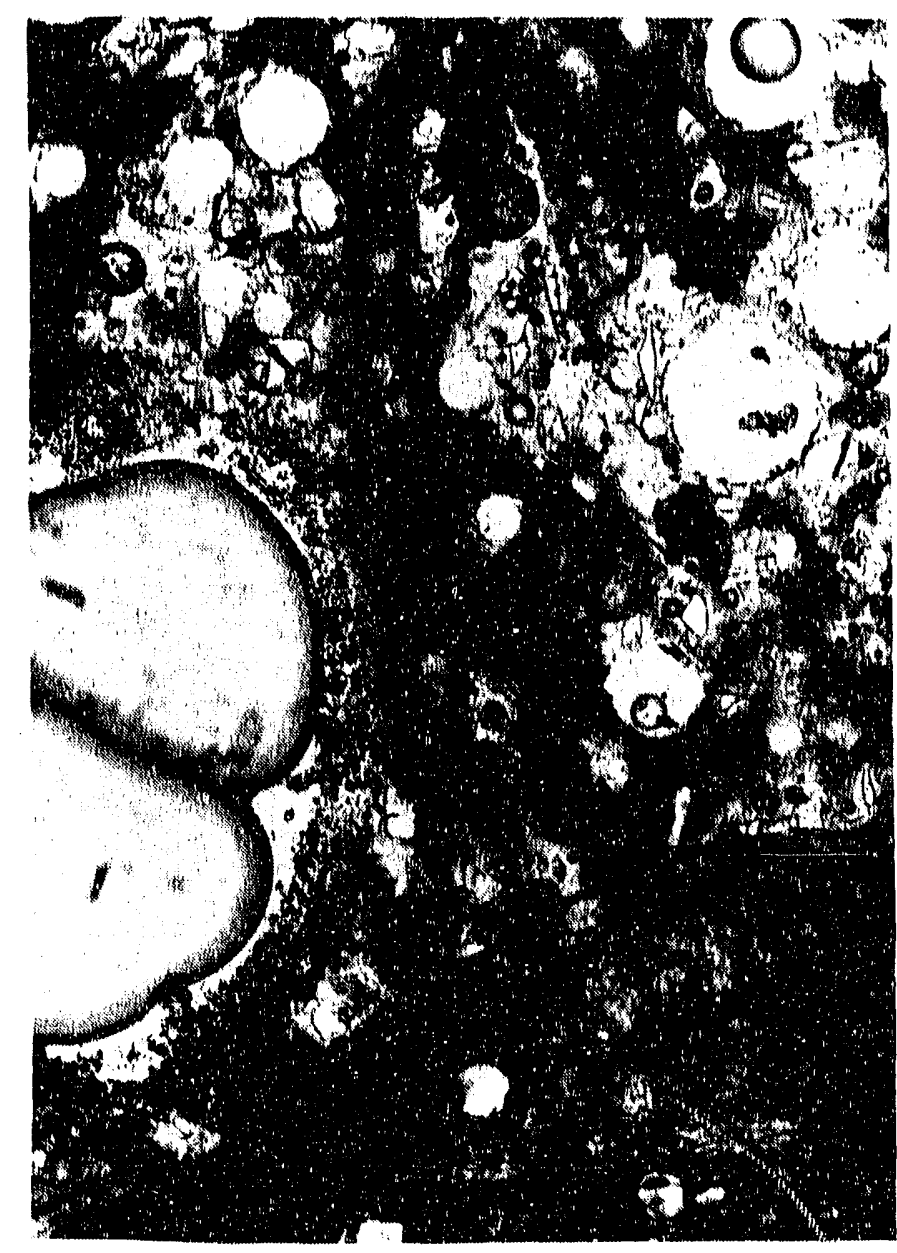

(a)

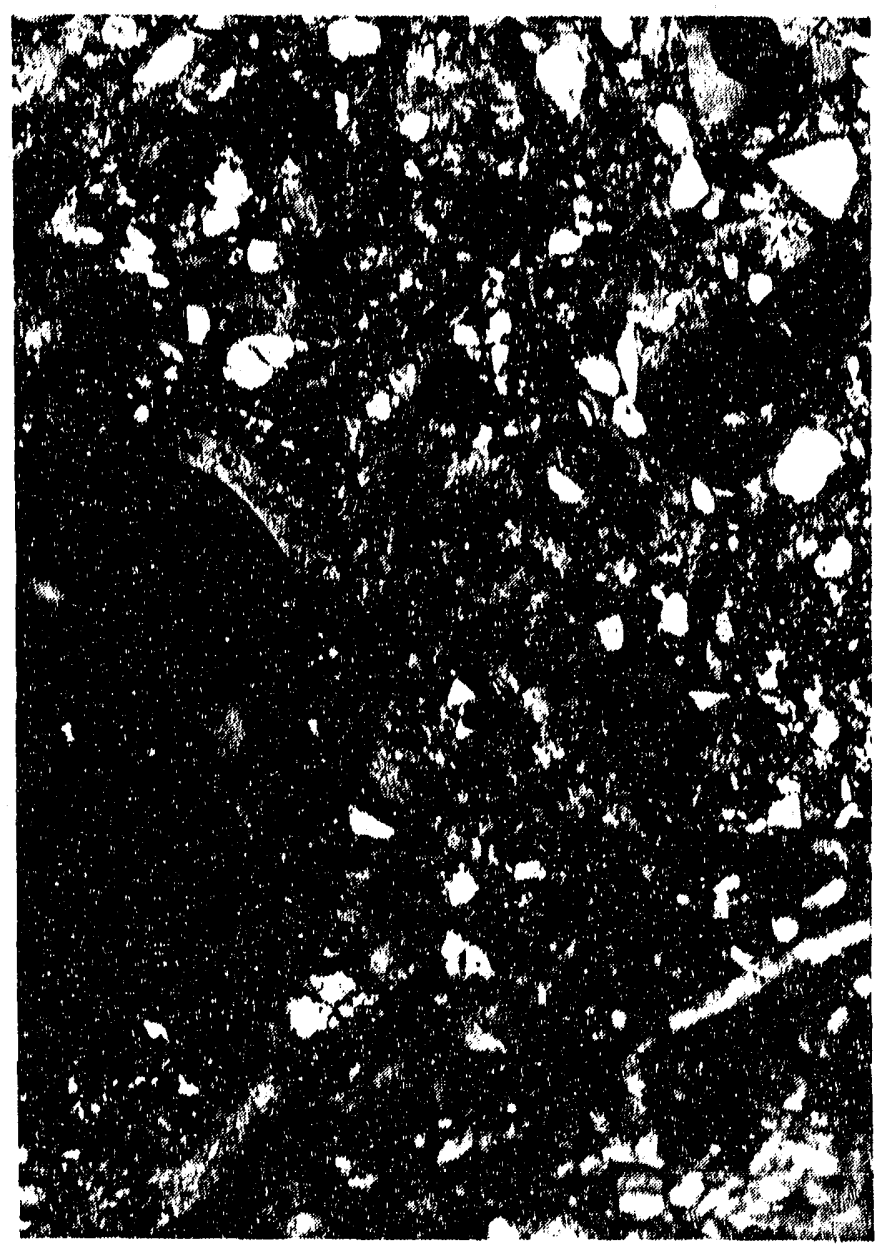

(b)

Figure 5. Photograph of rind in subsample IC502B90E6 at 100 times

magnification shown in plane polarized light with (a) no crossed nicol prisms and (b) crossed nicol frisms. (Photographs by C. R. Knowles.) 


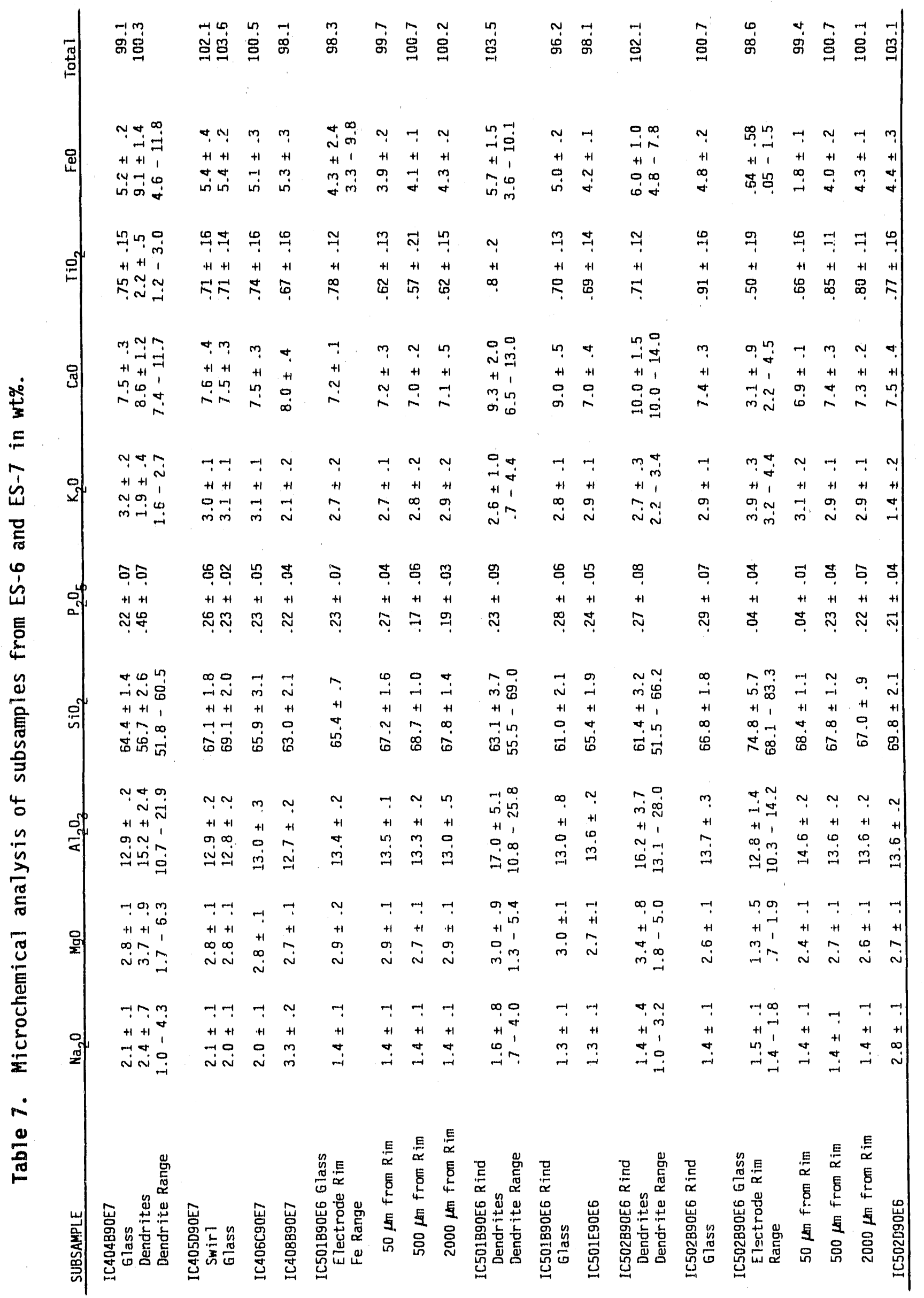




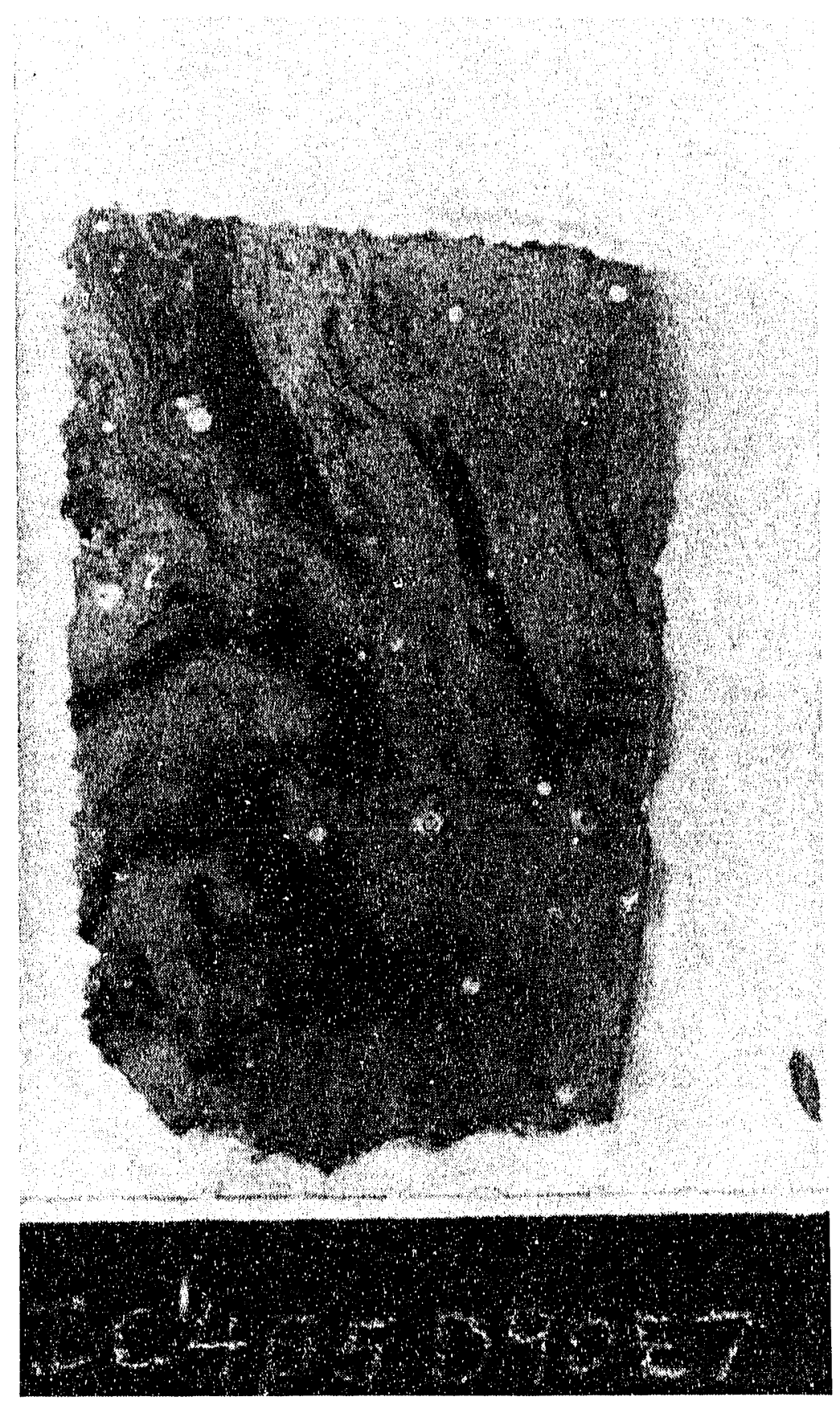

Figure 6. Petrographic polished thin section of subsample IC405D90E7. Glass slide measures $4.6 \times 2.7 \mathrm{~cm}$. (Photograph by C. R. Knowles.) 
Table 8. Microchemical analysis of metal inclusions in subsamples from ES-6 and ES-7 in wt\%.

\begin{tabular}{cccccc}
\hline Subsample & $\mathrm{Fe}$ & $\mathrm{P}$ & $\mathrm{Si}$ & $\mathrm{Ni}$ & $\mathrm{Cu}$ \\
\hline IC408B90E7 & $\begin{array}{l}74.4 \\
\text { Range }\end{array}$ & 10.2 & & 11.3 & \\
IC502B90E6 & & & & & \\
Glass & & & & & \\
Incl \#1 & 71.8 & 0.8 & 17.4 & 0.6 & 4.3 \\
Incl \#2 & 78.2 & 2.5 & 13.1 & 1.4 & \\
\hline
\end{tabular}

grayish cast, appeared to be composed of very small, round, opaque particles, which were barely discernable at 500 times magnification. The particles were, in some cases, accompanied by numerous small bubbles. Some of the sivirls that occurred around vesicies had a brown cast and were made up of dendrites. Some of the swirls were obviously derived from rind material. In other cases, the mineralogic composition of the swirls could not be discerned; the areas simply appeared brown in color, with no microstructure apparent. It is not uncommon to observe the different swirls alongside one another in a subsample. Microchemical analysis of the swirly pattern in subsample IC405D90E7 indicated that it has the same chemical composition as the glass matrix. The observed swirly patterns strongly suggest that mixing of the particles and melt edge material with molten material occurs through convection during the ISV process.

Areas near the rind have quartz grains which appear to be clustered around vesicles in the glass. This feature, observed with transmitted plane-polarized light and with the electron microprobe, is shown in Figures 7 and 8 . The quartz grains are detrital and come from the soil used in the test. The occurrence of vesicles near soil remnants suggests that the remnant quartz serves as a nucleation point for the vesicles.

The interface between a graphite electrode and the melt was al so examined. Figure 9 is a photomicrograph showing the electrode contact in transmitted planepolarized light and reflected light. The amount of metallic inclusions, which are dark in transmitted light but bright in reflected light, increase toward the electrode contact. The lineations seen in transmitted light are concentrations of bubbles. Quantitative microchemical analysis of the glass-graphite contact 


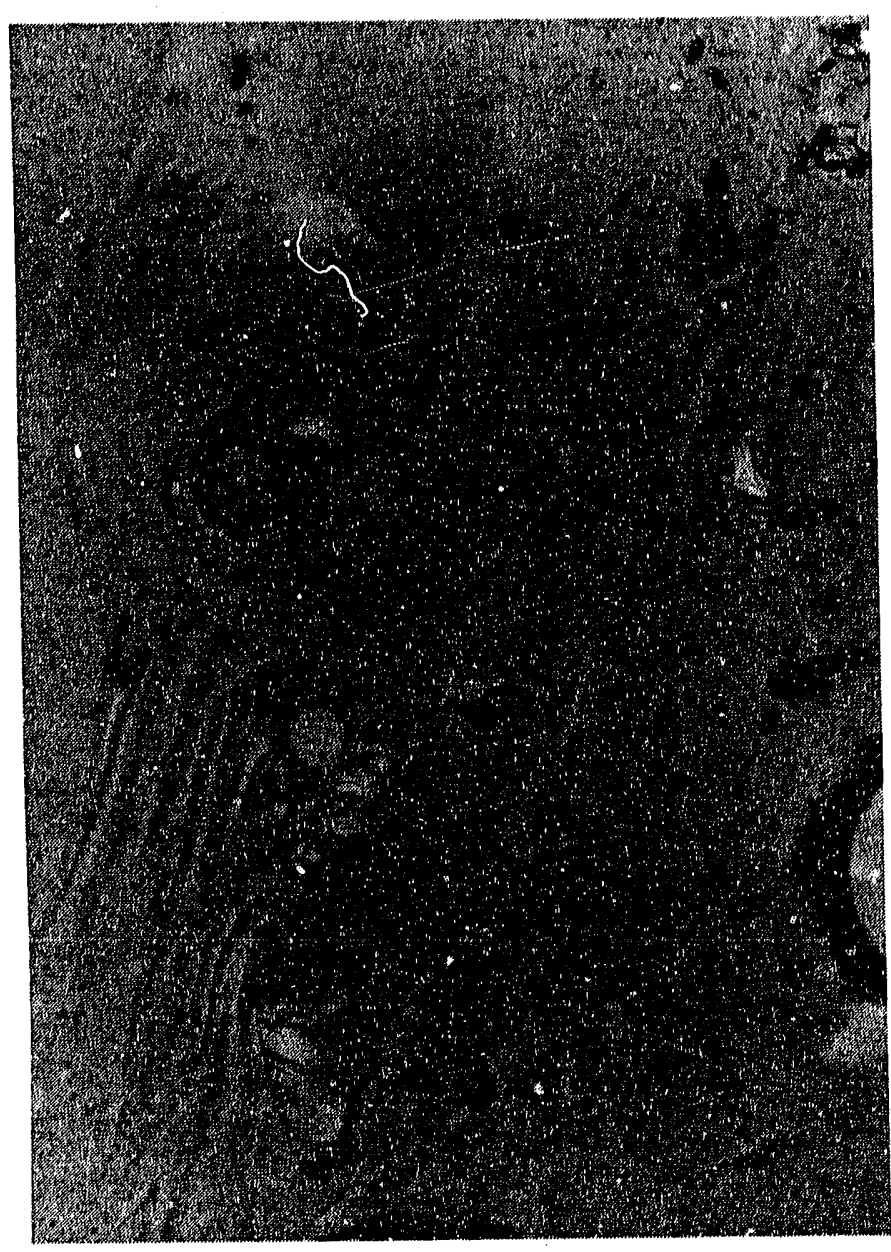

(a)

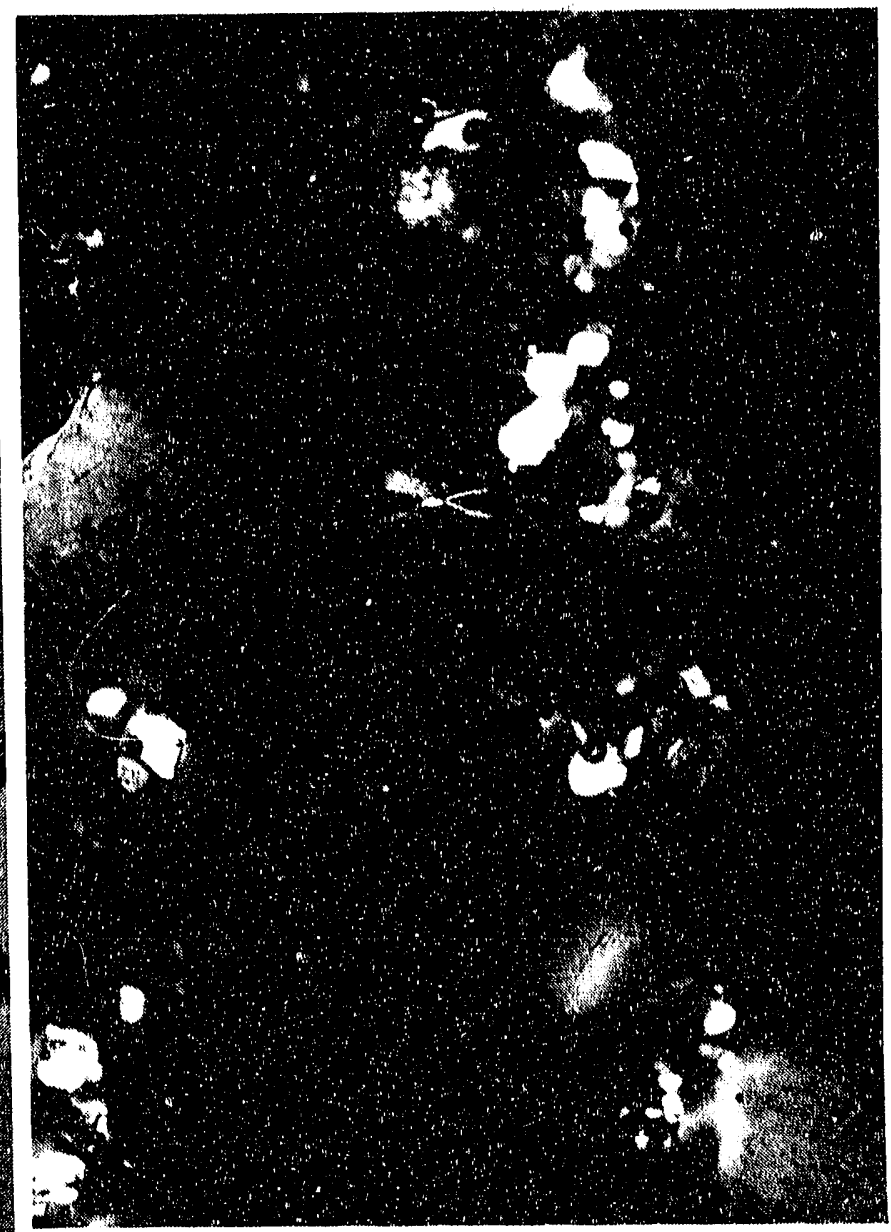

(b)

Figure 7. Photograph of glass with vesicles and quartz grains in subsample IC502B90E6 at 100 times magnification shown in plane-polarized light with (a) no crossed nicol prisms and (b) crossed nicol prisms. (Photographs by C. R. knowles.) 


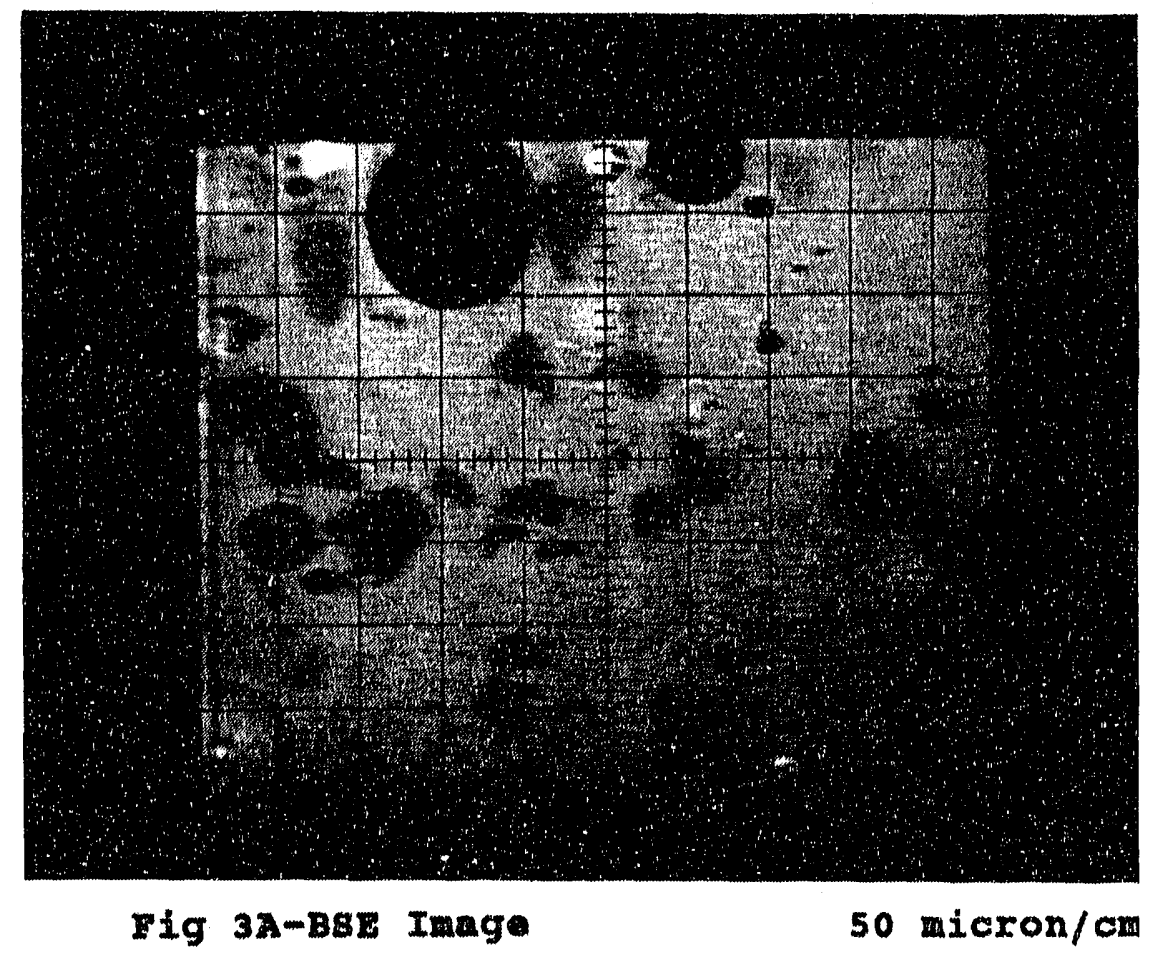

Figure 8. Electron microprobe backscatter electron image of quartz in subsample IC501B90E6 at 200 times magnification. (Photograph by C. R. Knowles.) 


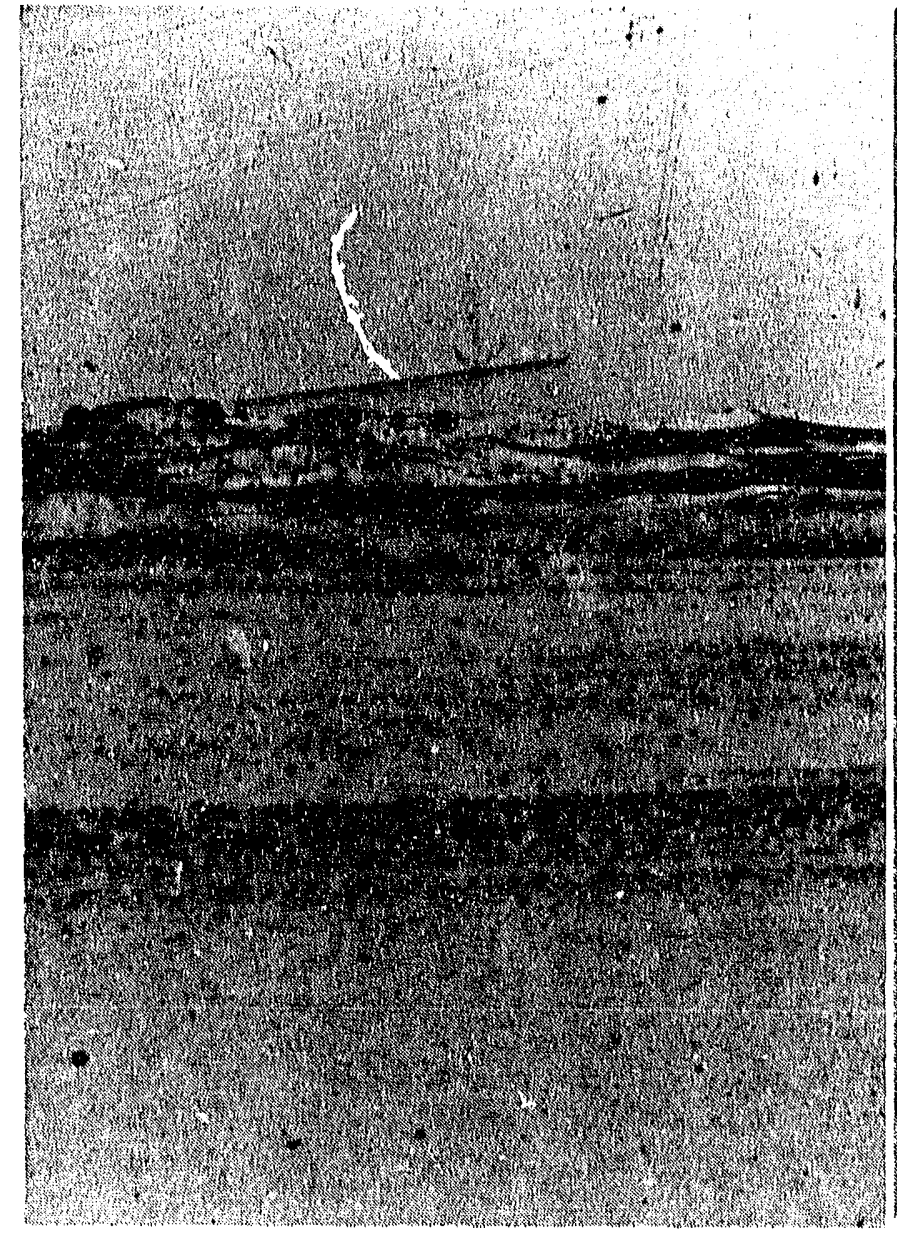

(a)

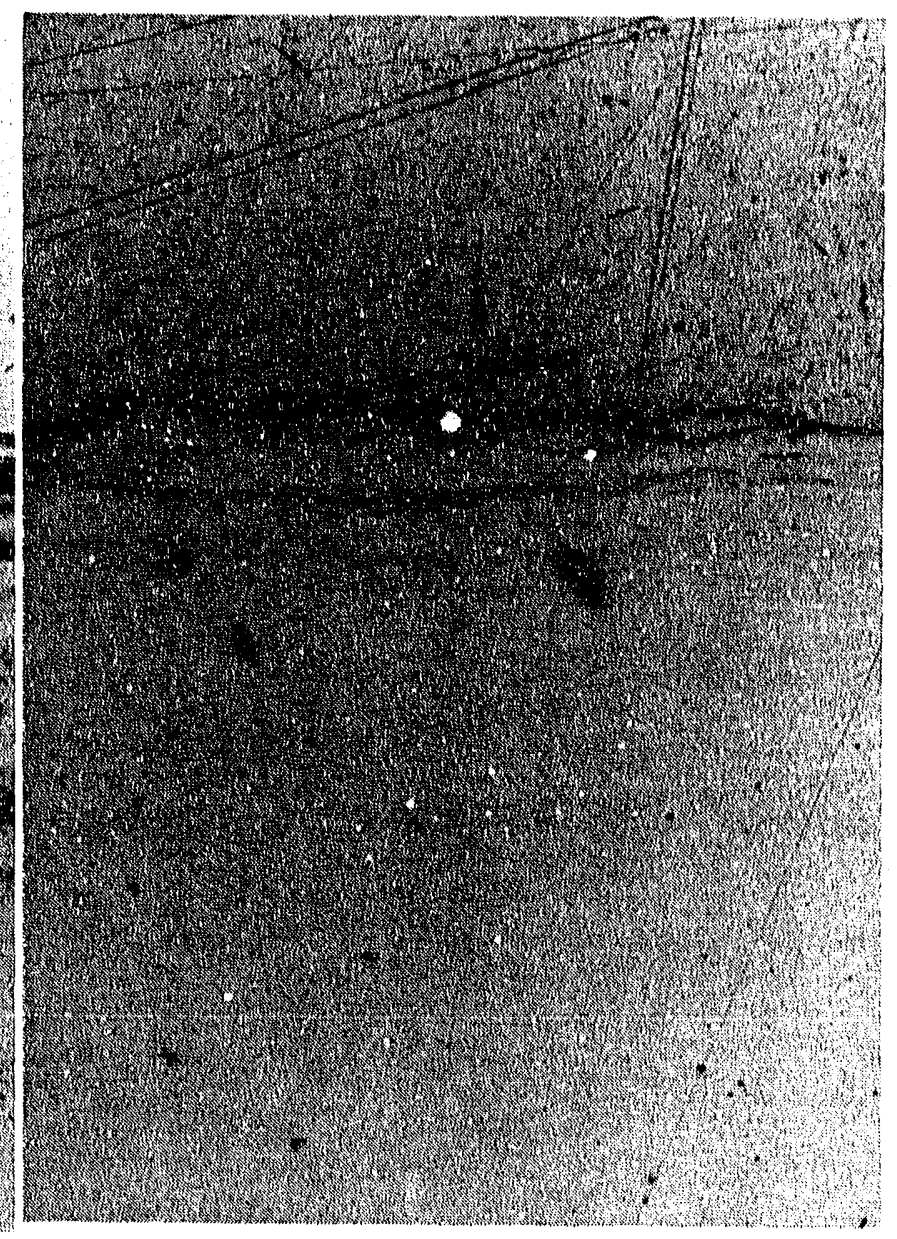

(b)

Figure 9. Photograph of glass at electrode contact in subsample IC502B90E6 at 100 times magnification shown in (a) plane-polarized transmitted iight with no crossed nicol prisms and (b) reflected light. Glass is shown in the bottom portion of the photographs. (Photographs by C. R. Knowles.) 
in subsample IC502B90E6 was carried out. The results show that the iron and phosphorous content of the glass systematically decrease toward the electrode as the number of metallic inclusions increase. The microchemical analysis shows that the silica content of the glass increases toward the graphite electrode. The behavior of the other major chemical elements is less well defined. The data suggest that the calcium, magnesium, and aluminum contents decrease toward the electrode, while the sodium and potassium contents increase toward the electrode. These data are direct evidence that the graphite electrodes reduce iron dissolved in the melt to the metallic state during ISV processing. Quantitative analysis could not be carried out on the metallic inclusions because of their small size. Qualitative data indicate that the inclusions are made up of two metallic iron phases, one rich in silicon, and the other rich in phosphorous, perhaps the compound $\mathrm{Fe}_{3} \mathrm{P}$. Quantitative data for subsample IC408B90E7 show a phosporous-rich metallic phase. The phosphorous occurs with iron as a rim on a pure iron center. This microstructure is shown in Figure 10.

Quantitative estimates of the bulk chemical composition of the waste form materials were made using the electron microprobe. The results of the analysis of several representative samples are shown in Table 7. Each datum

represents the mean value of about twenty individual measurements. In general, the glassy product materials are homogeneous at the macroscale and are very similar in chemical composition to the natural volcanic material andesite. The data may be qualitatively compared to INEL soil compositions shown in Table 2. Analyses on the specific soils used in the tests were not performed. The available data on INEL soil composition are quite variable and do not allow conclusions concerning the effect of vitrification of INEL soil and buried waste on product composition for these tests.

Table 9 gives the average, or mean, compositions of glassy product materials from the INEL IFT tests, ES-4, ES-6, and ES-7 (see References 3 and 5). The standard errors reported are influenced by the number of analyses that contribute to the mean, the analytical methods used, and sample variability. The data show that differences exist between some tests for $\mathrm{SiO}_{2}, \mathrm{FeO}, \mathrm{CaO}, \mathrm{Al}_{2} \mathrm{O}_{3}$, and $\mathrm{Na}_{2} \mathrm{O}$.

e. The variability could be because different laboratories performed the analysis and/or because samples came from inherently variable soil. 

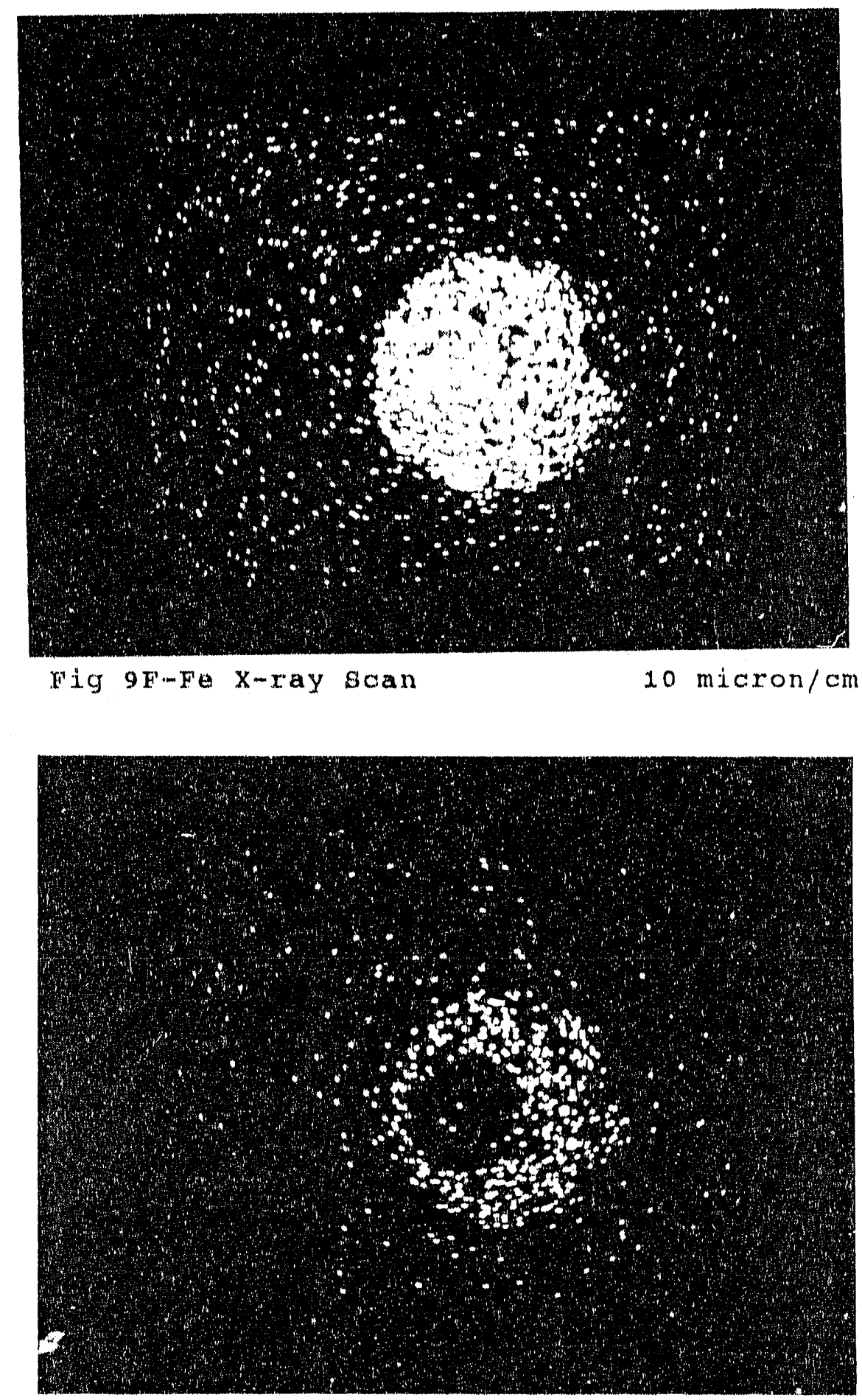

Figure 10. X ray dot map images of metallic iron inclusion with phosphorous rim in subsamplo 1040869067 . Shown are (a) fo $x$ ray scan and (b) P x ray scan at 1000 times machification. (Photographs by C. R. Konowlos.) 
Table 9. Average major element composition in weight percent of glasses from products of INEL tests. Standard errors of averages are shown in parentheses.

\begin{tabular}{|c|c|c|c|c|c|c|c|}
\hline Test & $\mathrm{SHO}_{2}$ & $\mathrm{FeO}$ & $\mathrm{MgO}$ & $\mathrm{CaO}$ & $\mathrm{Al}_{2} \mathrm{O}_{3}$ & $\mathrm{Na}_{2} \mathrm{O}$ & $\mathrm{K}_{2} \mathrm{O}$ \\
\hline IFT $-1^{b}$ & $\begin{array}{l}64.5 \\
(0.95)\end{array}$ & $\begin{array}{l}4.6 \\
(0.14)\end{array}$ & $\begin{array}{l}2.7 \\
(0.06)\end{array}$ & $\begin{array}{l}8.8 \\
(0.18)\end{array}$ & $\begin{array}{l}13.1 \\
(0.18)\end{array}$ & $\begin{array}{l}1.8 \\
(0.36)\end{array}$ & $\begin{array}{l}3.1 \\
(0.15)\end{array}$ \\
\hline IFT-2 & $\begin{array}{l}62.0 \\
(0.78)\end{array}$ & $\begin{array}{c}3.9 \\
(0.08)\end{array}$ & $\begin{array}{l}2.6 \\
(0.05)\end{array}$ & $\begin{array}{l}10.4 \\
(0.62)\end{array}$ & $\begin{array}{l}12.3 \\
(0.18)\end{array}$ & $\begin{array}{l}1.8 \\
(0.16)\end{array}$ & $\begin{array}{c}2.8 \\
(0.06)\end{array}$ \\
\hline$E S-4^{\circ}$ & 59.4 & 4.4 & 2.2 & 4.6 & 12.8 & 1.5 & 4.9 \\
\hline ES-6 & $\begin{array}{l}67.5 \\
(0.92)\end{array}$ & $\begin{array}{l}3.8 \\
(0.37)\end{array}$ & $\begin{array}{l}2.6 \\
(0.13)\end{array}$ & $\begin{array}{l}7.0 \\
(0.39)\end{array}$ & $\begin{array}{l}13.5 \\
(0.13)\end{array}$ & $\begin{array}{l}1.0 \\
(0.22)\end{array}$ & $\begin{array}{c}2.8 \\
(0.16)\end{array}$ \\
\hline ES-7 & $\begin{array}{l}65.6 \\
(1.31)\end{array}$ & $\begin{array}{c}5.25 \\
(0.06)\end{array}$ & $\begin{array}{l}2.8 \\
(0.02)\end{array}$ & $\begin{array}{l}7.6 \\
(0.12)\end{array}$ & $\begin{array}{l}12.8 \\
(0.06)\end{array}$ & $\begin{array}{c}2.35 \\
(0.32)\end{array}$ & $\begin{array}{l}2.9 \\
(0.26)\end{array}$ \\
\hline
\end{tabular}

a. The averages and standard errors are based on 4 analyses for ES-7, 12 for ES-6, and 1 for ES-4. IFT-1 means. are based on 7 analyses for al1 oxides except $\mathrm{StO}_{2}, \mathrm{Na}_{2} \mathrm{O}$, and $\mathrm{K}_{2} \mathrm{O}$, which are based on 5,4 , and 5 analyses, respectively. For IFT-2, 14 analyses contributed to the $\mathrm{SiO}_{2} \mathrm{O}$ mean, 12 to $\mathrm{FeO}, 15$ to $\mathrm{MgO}, 16$ to $\mathrm{CaO}$ and $\mathrm{K}_{2} \mathrm{O}, 17$ to $\mathrm{Al}_{2} \mathrm{O}_{3}$, and 13 to $\mathrm{Na}_{2} \mathrm{O}$.

b. IFT-1 and IFT-2 analyses are from Reference 3.

c. ES-4 analyses are from Reference 5 . 
Notably, however, ES-6 and ES-7 means are simflar to etther IFT-1 or IFT-2 or both for all major element oxides except $\mathrm{CaO}$ when the vartation is considered. ${ }^{f}$

f. $95 \%$ confidence intervals for the means were used in the comparison. 


\section{CONCLUSIONS}

Generally, the in situ vitrification (ISV) product was observed to be glass with a gray-vesiculated rilid about $10 \mathrm{~mm}$ thick. The waste and waste containers appeared to have been completely processed in the samples observed, except in and near the rind of some samples where container portions were intact. The glass fllling of the intact container portions contained $<1 \%$ unmelted materlal.

The products contafned metallic and crystalline phases in the glass. Commonly, several magnetic metal beads about $3 \mathrm{~mm}$ in diameter were observed in the samples. Round metallic inclusions of two distinct chemical types were also observed using the plane.polarized light microscope and with the election microprobe. Dendritic crystalline material of vartable composition, probably clinopyroxene, was also identified as a glass constituent. The rind was found to be composed primarlly of quartz and dendritic crystalline material that tended to surround areas of quartz. The observed relationship suggests that because the quartz had not been completely dissolved, the dendrites formed from and because of a silica deficient melt.

Round metallic inclusions were found to be either rich in silica or rich in phosphorous, the latter as an iron-phosphide rim on a pure iron center. The number of metallic inclusions increased toward the electrode contact while fron and phosphorous content of the glass decreased. The silica content of the glass increased toward the electrode. The data are direct evidence that the graphite electrodes reduce iron dissolved in the melt to the metallic state during ISV processing.

The glass contained swirls, prevalent near the sall edges, composed in some cases of dendrites and metallic inclusions. In some cases, the characteristics of the material could not be resolved; one analysis found the swirl to have the same composition as the glass. The swirls suggest that the melt mixing was incomplete at the soil edges.

Although the ISV product has a heterogeneous composition at the edges and nonvitreous phases are present in the product as a whole, the glassy phase is 
generally homogeneous at the macroscale. The glass is very similar in chemical composition to the natural volcanic material andesite.

The glass is vesicular, ranging from $<1 \%$ vesicles that are microscoptc in size to top surfaces that are virtually $100 \%$ vesicles that can be tens of millitmeters in diameter. Superimposed on this pattern are occastonal larger vesicles. In the rind, vestcles are gradational, increasing in diameter towards the glass. Also observed in the products near the rind are frequent occurrences of vesicles partially surrounded by quartz grains from the soll. It is posstble that the unmelted quartz serves as nucleation points for vestcles. This possible mechanism for the formation of vesicles and the relationships apparent in collected samples should be investigated in future studies on bubble formation in ISV melts.

The average chemical compositions of ES-6 and ES 7 glasses are similar, with one exception, to average compositions of IFT-1, IFT-2, and ES-4 glasses. MCC - 1 leach tests ${ }^{9}$ for IFT and ES-4 glasses indicate that the glasses are 10 times more durable than typical high-level nuclear waste borosilicate glasses. The ES-4 sample that was analyzed had normalized Si releases comparable to obsidian and granite. Intrinsic dissolution rates for IFT samples ranged from 0.01 to $0.06 \mathrm{~g} /\left(\mathrm{m}^{2} \mathrm{~d}\right)$ at $90^{\circ} \mathrm{C}$ and $\mathrm{PH}$ of 7. For the ES-4 sample, the intrinsic dissolution rate was $0.11 \mathrm{~g} /\left(\mathrm{m}^{2} \mathrm{~d}\right)$. The ES-6 and ES-7 glasses are expected to exhibit chemical durability characteristics similar to IFT-1, IFT-2, and ES-4 because chemical durability is a function primarliy of chemical composition. Because the ES-6 and ES-7 glasses are andesitic in composition, they would be expected to be stable in the natural environment for time periods similar to their natural counterpart.

Because of the potential sample mixup between ES- 6 and ES-7, differences between tests were not examined closely. However, the products are megascopically quite similar. This is noteworthy in view of the fact that test configuration differences could have lead to differences in cooling time and composition of the products. Insufficient data are available to comment on chemical differences between tests.

g. Tests performed for 28 days at $90^{\circ} \mathrm{C}$. 


\section{REFERENCES}

1. S. 0. Bates, In Situ Vitriffcation Waste Form Product Evaluation Strategy, EGG-WTD-9148, August 1990.

2. J. R. Weidner and $P$. R. Stoots, In Situ Vitriffication Engineering-Scale Test ES-INEL-4, ES-INEL-5, ES-INEL-6, and ES-INEL-7 Test PIan, EGG-WM-9090, Rev. 1, October 1990.

3. R. A. Callow, L. E. Thompson, J. R. Weidner, C. A. Loehr, B. P. McGratl, and S. O. Bates, In Situ Vitrification Application to Buried Waste: Final Report of Intermediate Field Tests at Idaho National Engineering Laboratory, EGG-WTD-9807, August 1991.

4. 3. W. Shade, R. K. Farnsworth, J. S. Tixier, and B. L. Charboneau, Enatneering-Scale Test 4: In Situ Vitrification of Toxic Metals and Volattle Organtes Burted in INEL Sotls, PNL-7611, June 1991.

5. C. A. Loehr, J. R. Weidner, and S. O. Bates, Product Evaluation of In Situ Vitrification Engineering Test 4, EGG-WTD-9868, September 1991.

6. P. R. Stoots, In Situ Vitrification Engineering-Scale Test ES-INEL-5 Test Plan, EGG-WM-9091, June 1990.

7. K. H. Oma, M. A. H. Reimus, and C. L. Timmerman, support for the In Sttu Vitrification Treatability Study at the Idaho Nattonal Engineering Laboratory: FY 1988 Summary, PNL-6787, 1989.

8. R. K. Farnsworth, K. H. Oma, and C. E. Bigelow, Initial Tests on In Situ Vitrification Using Electrode Feeding Techniques, PNL.-7355, May 1990.

9. R. K. Farnsworth, K. H. Oma, M. A. H. Reimus, Cructble Melts and BenchScale ISV Tests on Simulated Wastes in INEL Solls, PNL-7344, May 1990.

10. C. Timmerman, Geosafe Corporation, Kirkland, Washington, Iest Plan for In Situ Vitrification Engineering. Scale Test No. 6, EG\&G Idaho, Inc.s Job Number 318230, EGG-WTD-9597, March 1991.

11. C. Timmerman, Geosafe Corporation, Kirkland, Washington, Test Plan for In Situ Vitrification Engineering-Scale Test No. 7, EG\&G Idaho, Inc., Job Number 318220, EGG-WTD-9596, March 1991. 


\section{Appendlx A}

Qualitative Electron Microprobe Analysis 


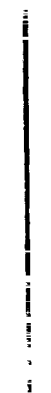

i

A-2

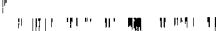




\section{Appendix A \\ Qualitative Electron Microprobe Analysis ${ }^{a}$}

\section{IC408B90E7}

Optically this sample has a discoloration fracture running across it. The discoloration seems to be the crack stress rather than a chemical change. There is a discoloration (more brown) near one edge. There is a quartz crystal surrounded by dark-brown dendrites. The rest of the sample is a homogeneous dark-green glass.

Very sma11, round, metal particles are present. They contain $\mathrm{Fe}, \mathrm{P}, \mathrm{Ni}$ and a small trace of As was verified as present using wavelength dispersive analysis.

The major elements in the glass matrix are Al, Si, K, Ca, Fe with trace amounts of $\mathrm{Ti}, \mathrm{Na}$ and $\mathrm{Mg}$. The dark discolored area seems to vary in $\mathrm{Ti}$ content more than the glass. The glass is lower in $\mathrm{Ti}$ than the discolored area.

\section{IC502D90E6}

Optically this sample has one vesicle near one edge that contains quartz and feldspar fragments that are not melted. The balance of the sample is a homogeneous dark-green glass with many vesicles. The EDX scan showed the carboncontaining holes had some $\mathrm{Cl}$ and $\mathrm{Cu}$ in minor amounts. One hole had $\mathrm{Cl}, \mathrm{Cu}$ and $\mathrm{Zn}$. This chemistry suggests debris in the hole and is not significant in the total picture of the glass chemistry.

Small metal inclusions of 2-5 micron in size were rare and scattered around in the glass. They contained $\mathrm{Fe}, \mathrm{P}$, and $\mathrm{Ni}$.

The major elements in the glass matrix are $\mathrm{Al}, \mathrm{Si}, \mathrm{K}, \mathrm{Ca}$, Fe with trace amounts of $\mathrm{Ti}, \mathrm{Na}$ and $\mathrm{Mg}$. The $\mathrm{Mg}$ may be a little larger in amount than in the previous two samples.

a. The qualitative SEM ana?ysis was nerformed and summarized by $C$. R. Knowles, Idaho Geological Survey, Moscow, Idaho. 


\section{$\underline{\text { IC406C90E7 }}$}

Optically this sample has a very homogerieous glass matrix with some very faint swirls of darker glass. The vesicles are round and no crystalline material was seen near the swirls, vesicles, or in the matrix.

Metal opaque grains were seen in the glass, however rare. They contain Fe, $\mathrm{Ni}$, and $\mathrm{P}$.

The major elements in the glass matrix are $\mathrm{Al}, \mathrm{Si}, \mathrm{K}, \mathrm{Ca}$, and $\mathrm{Fe}$ with trace amounts of $\mathrm{Ti}, \mathrm{Na}$, and $\mathrm{Mg}$.

\section{IC501E90E6}

This sample has a few swirls of darker glass when examined opticaily. The dark swirls seem to be the same chemistry but the Ti may vary. Some quartz crystals were observed near the vesicles. Zircon and quartz were present at one vesicle.

Metal opaque grains were seen from 1-3 microns in size. They contain $\mathrm{Fe}$ and $P$.

The major elements in the glass matrix are $\mathrm{Al}, \mathrm{Si}, \mathrm{K}, \mathrm{Ca}$, and $\mathrm{Fe}$ with trace amounts of $\mathrm{Ti}, \mathrm{Na}$, and $\mathrm{Mg}$.

\section{IC405090E7}

Many dark swirls of darker glass are seen in this sample optically. The chemical change in the clear and darker glass could not be seen qualitatively. Large (300-400 micron) quartz particles were observed with rounded edges. The appearance of the quartz grains seemed to be a welded composite of smaller quartz grains. The quartz was always near the vesicle wall when present.

Metal inclusions were present in very small amounts. They contain Fe and $P$ when large enough to analyze.

The major elements in the glass matrix are $\mathrm{Al}, \mathrm{Si}, \mathrm{K}, \mathrm{Ca}$, and $\mathrm{Fe}$ with trace amounts of $\mathrm{Ti}, \mathrm{Na}$, and $\mathrm{Mg}$. 
The major elements in the glass matrix are $\mathrm{Al}, \mathrm{Si}, \mathrm{K}, \mathrm{Ca}$, and $\mathrm{Fe}$ with trace amounts of $\mathrm{Ti}, \mathrm{Na}$, and $\mathrm{Mg}$.

\section{IC404B90E7.}

Optically this sample has a soil rind on one edge with gradation to homogeneous glass on one thin section. The glass has quartz crystals around some of the vesicles. The rind has many quartz crystals in a dark-brown dendritic matrix and glass interstitial in the dendritic pattern. The dendrites form rosettes in some areas near the edge. The dendrites diminish and disappear away from the soil (outer) edge. Parallel to the soil edge is a line of dendrites at the glass interface. The dark-brown dendrites seem to have formed from a thin line and grew outward from the line.

Tiny metal inclusions in the glass were present away from the rind edge. They were too small to analyze but were mostly $\mathrm{Fe}$ and $P$.

The chemistry is the same in the glass matrix as the other glass samples. The major elements in the glass matrix are $\mathrm{Al}, \mathrm{Si}, \mathrm{K}, \mathrm{Ca}$, and $\mathrm{Fe}$ with trace amounts of $\mathrm{Ti}, \mathrm{Na}$, and $\mathrm{Mg}$.

\section{IC501B90E6 GLASS}

The sample $501 B$ was made into two thin sections. One section is the glass matrix away from the soil edge (rind) and the other has the soil rind and gradation into the glass core.

The giass portion has some darker glass swirls and vesicles present. The vesicles have quartz crystals present around some of the larger ones. The quartz crystals are rounded.

The metal inclusions were rare but contained $\mathrm{Fe}, \mathrm{P}$, and $\mathrm{Ni}$. The particles were most abundant near the electrode contact edge. The zone of metal inclusions was in the 50 microns near the electrode contact and diminished toward the interior of the glass. 
The major elements in the glass matrix are $\mathrm{Al}, \mathrm{Si}, \mathrm{K}, \mathrm{Ca}$, and $\mathrm{Fe}$ with trace amounts of $\mathrm{Ti}, \mathrm{Na}$, and $\mathrm{Mg}$.

\section{IC501B90E6 RIND}

Optically the rind of this section has dark-brown dendrites in abundance near the edge and decreases in amount toward the glass. The sample has solid dendrites and quartz crystals with no or very little interstitial glass. Some zircons are present with the quartz.

Chemically the glass matrix is $\mathrm{Al}, \mathrm{Si}, \mathrm{K}, \mathrm{Ca}$, and $\mathrm{Fe}$ with varying amounts of $\mathrm{Ti}$ and traces of $\mathrm{Na}$ and $\mathrm{Mg}$. Some of the crystalline material seemed to have the same chemistry as the glass matrix. These crystalline grains may have been dendritic.

The metal inclusions were very scarce but present and small. They were Fe and $P$.

The major elements in the glass matrix are $\mathrm{Al}, \mathrm{Si}, \mathrm{K}, \mathrm{Ca}$, and $\mathrm{Fe}$ with trace amounts of $\mathrm{Ti}, \mathrm{Na}$, and $\mathrm{Mg}$.

\section{IC502B90E6 GLASS}

This sample 502B was made into two thin sections in order to see the soil (rind) edge and see the matrix glass away from the edge.

Optically this glass portion of the sample has darker glass swirls in the glass. There are quartz crystals around many of the vesicles. No dendrites or metal phases was observed in the glass matrix.

Examination of the electrode contact, showed black granular particles (carbon) present and many small metai inclusions in the nearest 50 micrometers to the contact. The metal inclusions we $\mathrm{Fe}, \mathrm{P}, \mathrm{Si}, \mathrm{Ni}$, and $\mathrm{Cu}$. There were several particles that contained $\mathrm{Si}$ and little $\mathrm{P}$ or they contained $\mathrm{P}$ and low Si. $\mathrm{Cu}$ was seen in one inclusion and $\mathrm{Ni}$ was common. 
The major elements in the glass matrix are $\mathrm{A}$, Si, $\mathrm{K}, \mathrm{Ca}$, and $\mathrm{Fe}$ with trace amounts of $\mathrm{Ti}, \mathrm{Na}$, and $\mathrm{Mg}$.

\section{IC502B90E6 RIND}

This sample of near the surface (rind) has all dendrites and quartz crystals at the edge and grades to less dendrites toward the core glass. The dendrites are very fine bundles and may have interstitial glass present but hard to see. Quartz surrounds all of the vesicles. Quartz crystals are large (100-200 microns).

Metal inclusions were present in the glass and rare in the rind edge. They were chemically $\mathrm{Fe}$ and $\mathrm{P}$.

The major elements in the glass matrix are $\mathrm{A} 1, \mathrm{Si}, \mathrm{K}, \mathrm{Ca}$, and $\mathrm{Fe}$ with trace amounts of $\mathrm{Ti}, \mathrm{Na}$, and $\mathrm{Mg}$. 


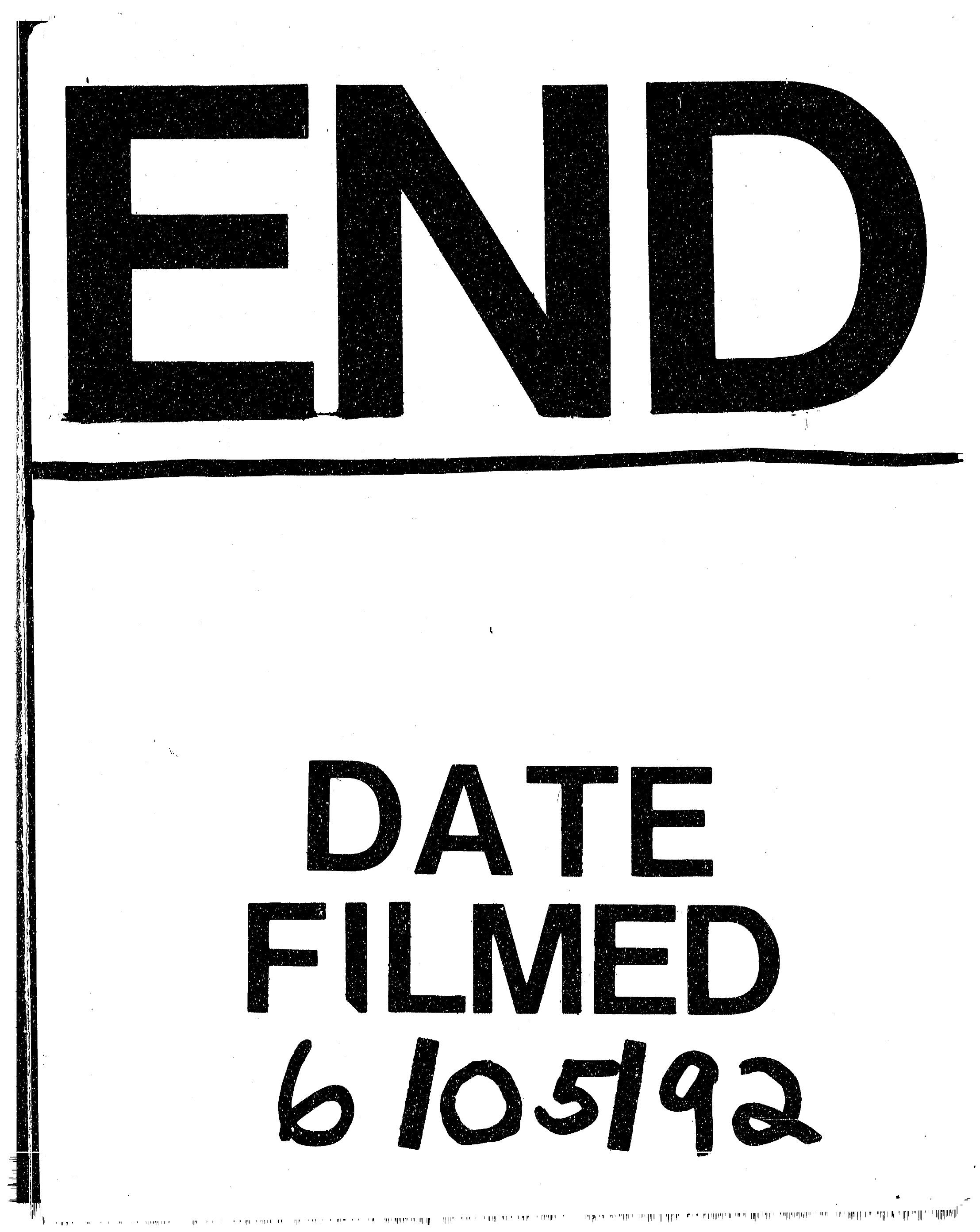


